Article

\title{
TerraSAR-X Data for High-Precision Land Subsidence Monitoring: A Case Study in the Historical Centre of Hanoi, Vietnam
}

\author{
Tuan S. Le ${ }^{1}$, Chung-Pai Chang ${ }^{1,2, *}$, Xuan T. Nguyen ${ }^{1}$ and Akano Yhokha ${ }^{2}$ \\ 1 Center for Space and Remote Sensing Research, National Central University, Zhongli District, \\ Taoyuan City 32001, Taiwan; tuanle@g.ncu.edu.tw (T.S.L.); xuannguyen@g.ncu.edu.tw (X.T.N.) \\ 2 Institute of Geophysics, National Central University, Zhongli District, Taoyuan City 32001, Taiwan; \\ akanoyhokha@yahoo.com \\ * Correspondence: cpchang@csrsr.ncu.edu.tw; Tel.: +886-3-422-7151 (ext. 57627); Fax: +886-3-425-4908 \\ Academic Editors: Zhong Lu and Prasad S. Thenkabail \\ Received: 21 February 2016; Accepted: 12 April 2016; Published: 19 April 2016
}

\begin{abstract}
In this study, subsidence patterns in the Historical Centre of Hanoi, Vietnam are mapped using the Interferometric Synthetic Aperture Radar (InSAR) technique, with particular emphasis on the stability of ancient monuments, historical buildings and archaeological sectors. Due to the small and scattered characteristics of these structures, not only is a comprehensive coverage of radar targets needed, but also the details of a single building or monument. We took advantage of the high-resolution TerraSAR-X imagery with the aid of oversampling implementation on the Small Baseline (SB) InSAR approach to reveal the subsidence patterns. A total of 6.29 million radar targets were obtained, maintaining the average density of 217,012 points $/ \mathrm{km}^{2}$. Our results suggest that image oversampling not only increased the number of measurement points 4.4 times more than the standard processing chain, but also removed some of the noisiest points. The observed subsidence patterns are mostly related to adjacent groundwater extraction and construction activities, with maximum subsiding rate reaching $-18.1 \mathrm{~mm} /$ year for the study period April 2012 to November 2013. Generally, heritage assets and monuments in the Citadel, the Old Quarter and French Quarter remain in a steady state, whereas those located along the Red River and in southern Hanoi are subject to subsidence.
\end{abstract}

Keywords: land subsidence; synthetic aperture radar; small baseline interferometry; TerraSAR-X; Historical Centre of Hanoi; heritage culture assets

\section{Introduction}

Hanoi, the capital of Vietnam, has been the largest economic and cultural center of the country for thousands of years. The city is where most Vietnamese dynasties left their imprints, and many relics of these eras still exist in the region. However, due to the ravages of time, ancient monuments and heritage sites in Hanoi are deteriorating, thereby threatening the lives and safety of local residents. A typical example is the total collapse of an ancient French villa at 107 Tran Hung Dao Street which killed two persons and wounded five others. The incident, which happened on 22 September 2015, underscored the serious safety risks for those living near ancient monuments and structures.

Since the beginning of the 1990s, a great deal of effort has been made by researchers to assess land subsidence phenomena in Hanoi, including methods based on soil characteristics, water flow modeling [1-3], differential SAR interferometry [4,5] and the multi-temporal Interferometric Synthetic Aperture Radar (InSAR) [6,7]. Although they have derived a relatively complete subsidence map of Hanoi city, there has been no detailed data for the Historical Centre for the following reasons: (1) Research scope: Land subsidence with the velocity of several millimeters per year at building scale 
could be easily neglected because of high rates of land displacement in industrial and suburban areas; (2) Data limitation: Only L- and C-band SAR wavelengths have been taken into account. Despite their better penetration capabilities, X-band SAR sensors have the obvious advantage of being able to monitor small-scale movements of small objects, especially in urban areas where there is less vegetative cover [8]; (3) Computational and method limitations: To optimize for a wide monitoring scale range, the small details and precision had to be forfeited.

In order to fill this gap, the multi-temporal InSAR techniques are employed to highlight the ground evolution of the Historical Centre of Hanoi and surrounding area. Furthermore, image oversampling was implemented, for the first time, into the Small Baseline (SB) InSAR processing chain to enhance the level of detail and coverage that could be achieved. We apply those techniques to a set of high-resolution TerraSAR-X images because of their shorter wavelength and finer spatiotemporal resolution. In the following, the two results obtained with and without oversampling are analyzed to investigate the influences of oversampling implementation on the SB InSAR processing chain. The InSAR results are then compared with surface geology and optical images to interpret the causes of observed subsidence patterns.

This paper is organized as follows. Section 2 gives an overview of the natural and historical background of the study site. After summarizing the data used (Section 3), the SB InSAR approach and the techniques used in this study are described step by step in Section 4. Along with discussing observed subsidence patterns and their influences on cultural heritage sites, we perform the comparison between the results derived with and without oversampling (Section 5). Conclusions and potential extensions of this work are provided in Section 6.

\section{Study Area}

Hanoi city is located in the northwest of the Red River delta, northern Vietnam. This city occupies an area of $3328.9 \mathrm{~km}^{2}$, which is the second largest city in the country. After four administrative expansions, it is currently divided into 12 urban and 17 suburban districts. The population of the city has doubled to 6.7 million people over the last decade. The average population density reached 1979 per $\mathrm{km}^{2}$ whereas the highest density recorded is 35,341 per $\mathrm{km}^{2}$ in Dong Da district [9].

Hanoi is characterized by a flat, homogeneous topography, lower in the northwest than the southeast with the variation from 12 to $5 \mathrm{~m}$ above sea level. This area is underlain by Quaternary sediments comprised of different formations divided by $t$ origin and age. The upper part consists of Late Holocene alluvial and Early-Middle Holocene deposits, marine soil, and lacustrine. The deeper part is the combination of Late Pleistocene alluvial; lacustrine; Middle-Late Pleistocene alluvial; alluvial-proluvial deposits; and Early Pleistocene alluvial deposits $[3,10]$. The surface geology of the study area is depicted in Figure 1.

As shown in Figure 1, we selected the Historical Centre of Hanoi city as the study area. The area of this site is $28.9 \mathrm{~km}^{2}$, mostly belonging to administrative zones of the four districts, Hoan Kiem, Ba Dinh, Dong Da and Hai Ba Trung. As mentioned in Section 1, Hanoi has traditionally been the capital of Vietnamese imperial dynasties in the past. Although some relics have not survived time and wars, there are still numerous heritage sites and structures that exist in the area, and more than 600 of these have been explored and indexed by the local government. There is more diversity of archaeological findings in Hanoi than in any other Vietnamese city due to the influence from various cultures around the world, including Taoism (Temple of the Jade Mountain), Confucianism (The Temple of Literature), Buddhism (One Pillar Pagoda, Hoe Nhai Pagoda), Catholicism (St. Joseph's Cathedral, Roman Catholic Archdiocese of Hanoi) or Western civilization (Presidential Palace, Hanoi Opera House), etc. 


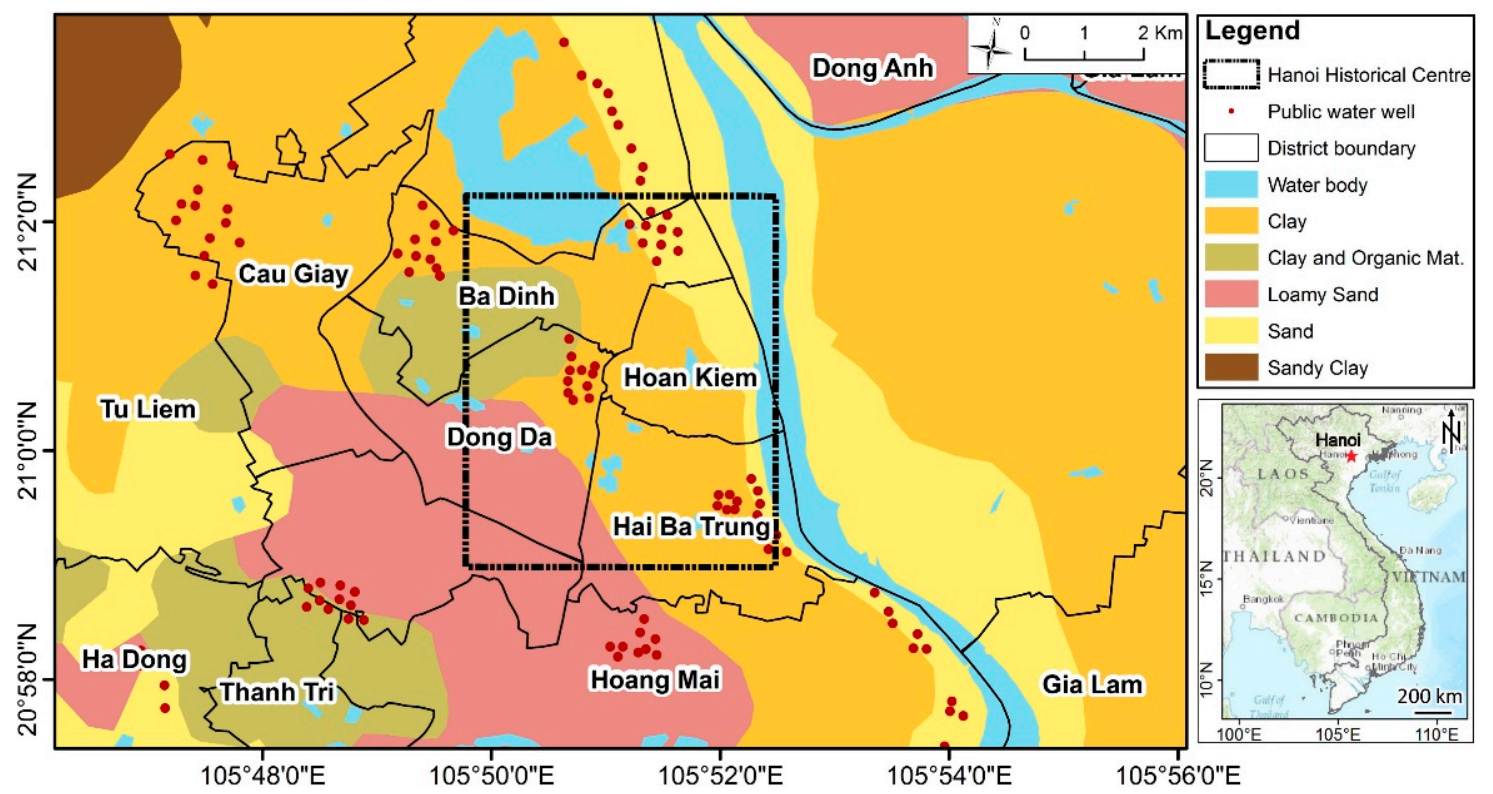

Figure 1. Surface geology map (after Nguyen [11]) and location of the Historical Centre of Hanoi.

\section{Data Availability}

Satellite SAR imagery acquired by the German satellite TerraSAR-X and its twin, TanDEM-X, were analyzed in this study. We used 23 SAR acquisitions for the time span of 20 months, from 10 April 2012 to 25 November 2013. They are in Stripmap strip_010 Beam mode, single HH polarization, with an incidence angle that varies from $36^{\circ}$ to $38.5^{\circ}$ at near and far range, respectively. The wavelength of those acquisitions is $31 \mathrm{~mm}$, which corresponds to X-band in the microwave spectrum. Generally, $\mathrm{X}$-band is less suitable for a vegetated area due to the limited penetrating capability compared to L- or even C-bands; however, it is approximately twice as sensitive to small deformation incidents [12]. In addition, the higher resolution ( $3 \mathrm{~m}$ ) and shorter revisit frequency (up to 11 days) of the $X$-band TerraSAR-X imagery enable mapping the deformation patterns with the details that could not be detected by any longer wavelengths. Moreover, the land cover of Hanoi Historical Centre is predominantly comprised of an urban area and the temporal decorrelation is relatively low, indicating that the expected ground displacement is at the sub-centimeter level. Therefore, X-band SAR data is considered more suitable for monitoring the deformation over this area than other SAR wavelengths.

On the other hand, the Shuttle Radar Topography Mission (SRTM) Digital Elevation Model (DEM) version 3, provided by NASA through Land Process Distributed Active Archive Center, was used to remove the topographic components from SAR interferograms. The DEM, which was derived from C-band radar interferometry technique [13], is recently covering the study area with data posting at 1 -arc-second intervals ( $30 \mathrm{~m}$ spatial resolution). This is considered the best DEM data for this area because there has been no campaign for constructing regional DEM and since the quality of SRTM DEM is significantly improved in this version. Data from the ASTER GDEM2 and the USGS GMTED2010 elevation model were used to fill the voids, thereby overcoming the most common drawback of interferometric DEM [14].

\section{Interferometric Synthetic Aperture Radar (InSAR) Time Series Analysis}

SB methods [15-17], one of the board categories in InSAR techniques, takes advantage of the maximum-coherence interferograms to detect the underlying signal in the Slowly Decorrelating Filtered Phase pixels (SDFP) [17]. Unlike standard SB methods, the Stanford Method for Persistent Scatterer (StaMPS) SB processing chain has the ability to work on the highest resolution of single-look SAR images, and isolated SDFP could be potentially separated among completely decorrelated pixels [17]. 
In this study, we integrated the oversampling implementation into the StaMPS SB approach for better collection of detail and coverage. Figure 2 represents the simplified flow chart used in this study, which divides the SB InSAR processing into three main steps: image oversampling, interferometric processing and SB time-series processing. Details of each step are described in the following subsections.

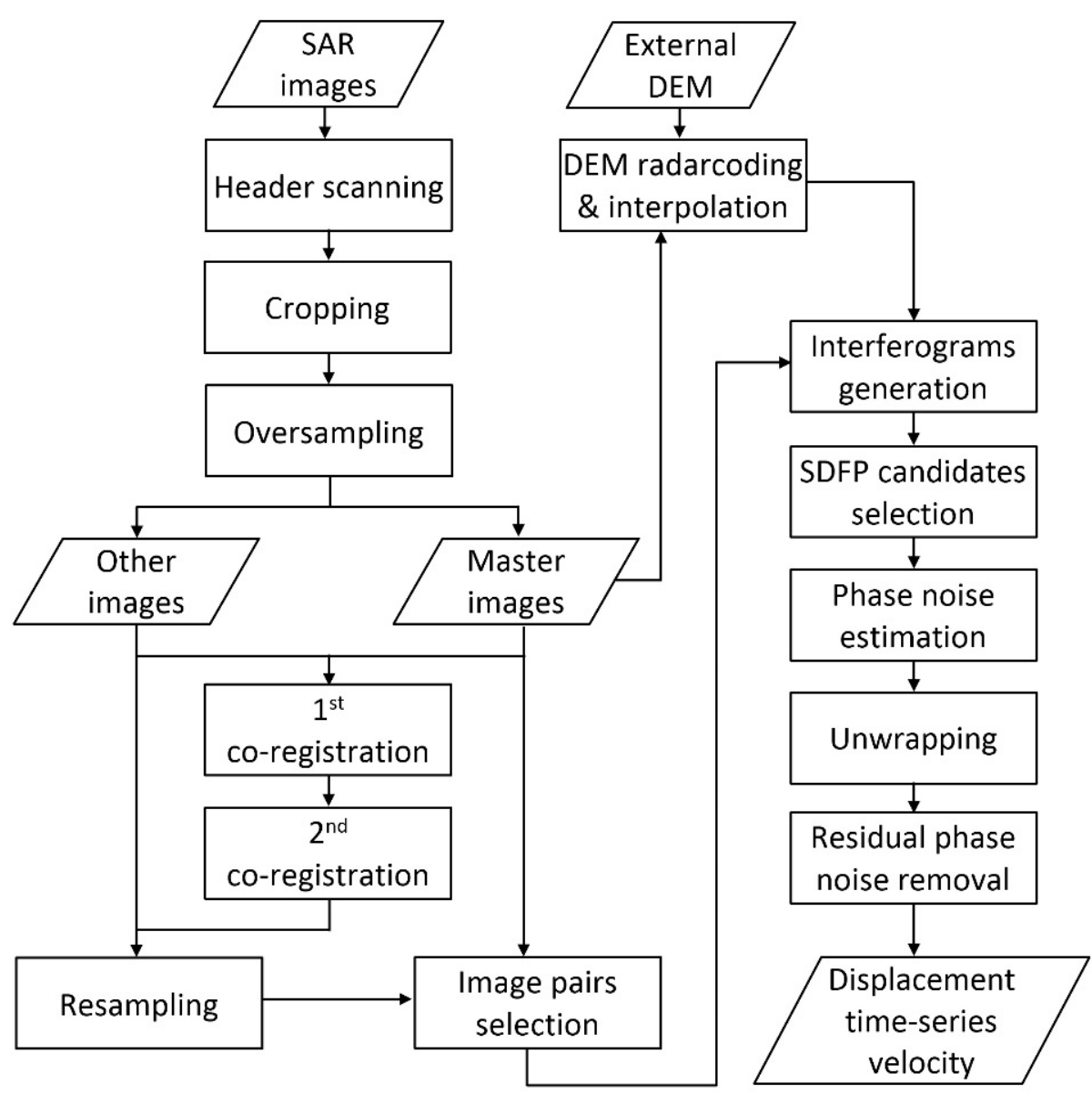

Figure 2. Flowchart of Small Baseline (SB) processing with image oversampling implemented.

\subsection{Oversampling Implementation}

In InSAR processing, image oversampling is a noticeable approach to enhance the monitoring detail and coverage by increasing the number of point-wise measurements. Despite limitations, which are mostly due to the additional computation required, the positive impacts of oversampling on the Persistent Scatterer Interferometry (PSI)—another board of the InSAR technique-were successfully described in [18-20].

Oversampling is performed to overcome the aliasing problem, which usually occurs in the complex multiplication of the two SAR images to form the SAR interferogram [19,21]. After a single-look SAR image is oversampled, its pulse repetition frequency is doubled, thus the scattering signal could be located with higher accuracy. In other words, the signal of an object in an oversampled image's radar coordinate could be detected with sub-pixel precision, as compared to a non-oversampled image. This implies two major influences to InSAR results: (1) Enhancing the precision in co-registration of the two SAR images; (2) Increasing the number of point-wise measurement targets, in this case: number of SDFP that could be detected. In fact, oversampling is commonly implemented in some PSI processing procedures, e.g., as a mandatory step in the Delft 
PSI processing package (DePSI) or an optional step in the StaMPS PSI processing chain. However, oversampling has not been applied to SB approaches despite its potential.

The aliasing problem caused in InSAR processing is induced by the bias between the true Doppler centroid and the flight direction, which leads to the whole SAR spectrum shifting in azimuth direction [18,21]. Therefore, we took into consideration the Doppler centroid frequency shift to evaluate the reasonable oversampling factor for the available TerraSAR-X data. An oversampling factor of 2 was considered as sufficient to avoid the aliasing of Doppler shift up to $990 \mathrm{~Hz}$ [18]. Thanks to the favorable orbit control, SAR acquisitions used in this study have very low Doppler centroid frequency (normally smaller than $100 \mathrm{~Hz}$ ).

Therefore, in this study, SAR images were oversampled by a factor of 2 in both range and azimuth direction after cropping and before taking into interferometric processing. All the images, except the common master one, were cropped by applying a deviated frame of 50 pixels in order to reverse pixels for the frame shifts that could happen in the co-registration step.

\subsection{Interferometric Processing}

We started by selecting the common master image as the acquisition taken in 5 November 2012; each of the remaining 22 images was individually co-registered and resampled to the cell size and coordinate of the master image. Then, image co-registration was performed by a two-step procedure. In the first step, the correlation of magnitude images was evaluated in the spectral domain to calculate the temporary offset at pixel level for the whole image in both range and azimuth direction. The temporary offset between master and slave image is assigned as the most frequently occurred offset value among 100 different geometrically distributed positions. In each position, we calculate the different offsets in a specific measurement window: the one with highest correlation value was chosen as the input for the next step [22]. The second co-registration step is developed to adjust the alignments between master and slave images at sub-pixel level by calculating the maximum correlation value in oversampled windows, which were interpolated by the use of Fast Fourier Transform. We used a smaller size but bigger number of windows compared to the first step to maintain both computation efficiency and co-registration accuracy. Finally, the slave images were resampled to the cell size of master image by using the parameters provided by the two-step co-registration. The resampled slave image was again co-registered to the common master grid in order to confirm the accuracy of resampling procedure, which the average value of the offset vectors should be zero.

The interferograms were generated by applying the conventional two-pass Differential InSAR (D-InSAR) approach [23-25], which takes into account the phase components of pre-selected image pairs for the complex multiplication. The flat earth and topographic phase contributions were subtracted from the complex interferograms by using the precise orbit provided in images' header and the radarcoded 1-arc-second SRTM DEM, which is previously described in Section 3. Compared to the fine resolution of TerraSAR-X images, the $30 \mathrm{~m}$ resolution of SRTM DEM is considered as coarse to completely remove the topographic phase components. However, thanks to the small baselines of the images and the fact that our area of interest is only $28.9 \mathrm{~km}^{2}$ on a fluvial plain, this potential error can be neglected. Eventually, an adaptive filtering algorithm was applied to reduce the phase noise and sharpen the interferometric fringes (see Goldstein and Werner [26]).

Under the procedure described above, we constructed 52 interferograms from 23 initial TerraSAR-X images by applying the thresholds of $0.6,500 \mathrm{~m}$ and $300 \mathrm{~Hz}$ for estimated coherence, perpendicular baseline and Doppler centroid, respectively. The baseline information is shown at Figure 3. The Delft Object-Oriented Radar Interferometric Software (DORIS) [27] was used for generating the interferograms. 


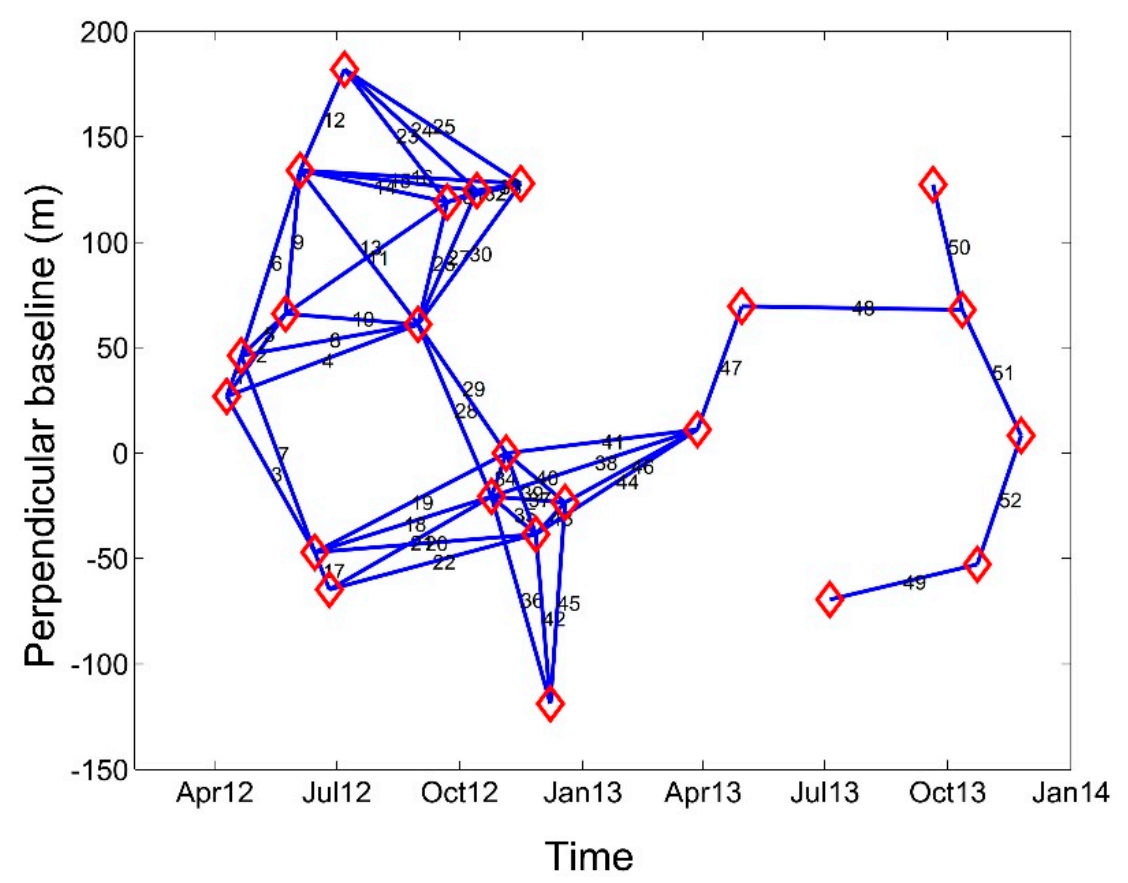

Figure 3. Baseline information of interferometric pairs. Lines represents 52 SB interferograms formed. Red diamonds represent SAR acquisitions.

\subsection{Small Baseline (SB) Time-Series Processing}

To start the StaMPS SB algorithm, an initial set of SDFP candidates was selected to reduce the number of pixels needed to be processed, thus improving the computational efficiency. Despite the consideration of assigning a pixel as a SDFP pixel base on phase analysis, Ferretti, Prati and Rocca [28] show that the amplitude and phase stabilities have a certain relationship. Therefore, we used the threshold defined by them [28], which is called the amplitude dispersion index:

$$
D_{A}=\frac{\sigma_{A}}{\mu_{A}} \cong \sigma_{\varphi}
$$

where $\sigma_{A}$ is the amplitude standard deviation, $\mu_{A}$ is the mean amplitude and $\sigma_{\varphi}$ is the standard deviation of the SAR image's phase component. A relaxing threshold $D_{A}=0.65$ was used for this TerraSAR-X stack as every target with $D_{A} \leqslant 0.65$ is considered a SDFP candidate.

After an initial set of SDFP candidates was identified, the SDFP pixels were separated from SDFP candidates using the algorithm proposed by Hooper [17] and Hooper et al. [29], which divides the phase error terms into two main components: those which are spatially correlated and those which are spatially uncorrelated. The spatially correlated error comprises the contribution of ground displacements, the instability of satellite orbit, atmospheric delay and topographic residual phase components. Assuming that the movement of objects on the ground is correlated in spatial domain, the combination of a low-pass filter and an adaptive phase filter is applied for every neighbor pixel to estimate the spatially correlated phase errors. Furthermore, the spatially uncorrelated phase components, mainly caused by a shift of the pixel phase center from its physical center and the DEM-induced error, are estimated by evaluating the correlation with the perpendicular baseline [17]. The residual phase noise for SDFP candidates is estimated by subtracting the two components: spatially correlated and spatially uncorrelated phase noise are specifically represented by $[17,29,30]$ :

$$
\gamma_{x}=\frac{1}{N}\left|\sum_{i=1}^{N} \exp \left\{\sqrt{-1}\left(\psi_{x, i}-\widetilde{\psi}_{x, i}-\Delta \hat{\phi}_{\phi, x, i}^{u}\right)\right\}\right|
$$


where $\hat{\phi}_{\phi, x, i}^{u}$ is the estimate of the spatially uncorrelated look angle error component and $\widetilde{\psi}_{x, i}$ is the estimate of the spatially correlated error component of the wrapped phase $\psi_{x, i}$ of the $x^{\text {th }}$ pixel in the $i^{\text {th }}$ interferograms.

Phase components of chosen SDFP pixels were then unwrapped by the method proposed by Hooper and Zebker [31]. It can be assumed that the residual spatially correlated phase noises after unwrapping are primarily induced by the atmosphere and the instable orbits and do not correlate in the temporal domain as the ground displacements most likely do. Therefore, we applied high-pass filtering in the time domain and low-pass filtering in space to remove the residual phase errors $[22,28,29]$.

\section{Results and Discussion}

Because no active fault and ground fissure activity have been reported in our study area and because SAR is more sensitive to vertical than horizontal displacements [32], it could be assumed that the measured Line of Sight (LOS) movements are purely contributed by the vertical component of surface displacement. This assumption is supported by the fact that massive water pumping and construction activities play important roles in land subsidence phenomena in Hanoi city [6,7]. Therefore, we project $\operatorname{LoS}\left(V_{L O S}\right)$ to vertical $\left(V_{v}\right)$ displacement for every SDFP based on TerraSAR-X mean incidence angle $\left(\theta=37.3^{\circ}\right)$ and the projection equation: $V_{v}=V_{L O S} / \cos \theta$. The projected vertical velocity is $25.7 \%$ more than the original LoS velocity. From here the projected vertical displacements $\left(V_{v}\right)$ are used to discuss the velocity of subsidence, although both $V_{v}$ and $V_{L O S}$ are shown in the legend.

Figure 4a represents the location of noticeable heritage culture sites in the study area, overlying an optical satellite image which was taken in September 2012. Figure $4 \mathrm{~b}$ shows the average land subsidence map of Hanoi Historical Centre from 10 April 2012 to 25 November 2013. Blue color stands for uplift whereas warm color stands for subsidence behavior of the surface. In total, we observed 6.29 million SDFP over an area of $28.9 \mathrm{~km}^{2}$, maintaining the mean SDFP density of $217,012 \mathrm{SDFP} / \mathrm{km}^{2}$. Generally, the InSAR result suggests that subsidence patterns spotted in the area of the Old Quarter, French Quarter and Ba Dinh Quarter, where most of the monuments and archaeological sites are located, are at a relatively low rate and small scale. The subsidence bowls appeared predominantly in the new residential areas of Cau Giay, Hai Ba Trung and Thanh Xuan district. The maximum average subsidence rate reached $-18.1 \mathrm{~mm} /$ year. It is worth noting that subsidence patterns are extensively distributed along the Red River bank, although the velocity only fluctuates around $1 \mathrm{~cm}$ per year.

In order to assess the influences of oversampling implementation on SB InSAR processing, an SB InSAR result without oversampling was also prepared for comparison purposes. A remarkable increment of SDFP was recorded by applying oversampling into the SB InSAR processing chain. Specific tests were applied to both standard and oversampled results, which are presented and discussed in Section 5.2.

\subsection{Land Subsidence Assessments of Hanoi Historical Centre}

There are 18 subsidence patterns selected for further analysis and interpretation because they are considered the driving factors behind the ground stability of culture heritage sites or, conversely, the risks posed to adjacent buildings and structures. The location of selected patterns is depicted in Figure 4b (denoted with label S1-S18) and divided into four groups, including: The Citadel (S1-S3), monuments on the Red River bank (S4-S6), the Old Quarter and French Quarter (S7-S9) and prevailing subsidence patterns (S10-S18). All groups are analyzed and summarized in Table A2 and discussed in the following subsections. The figures are arranged as follows: (1) the average LoS velocity map of subsidence patterns; (2) the average temporal evolution of SDFP observed in subsidence center; and (3) the shape of subsidence pattern and the nearby construction sites on optical images. 
(a)

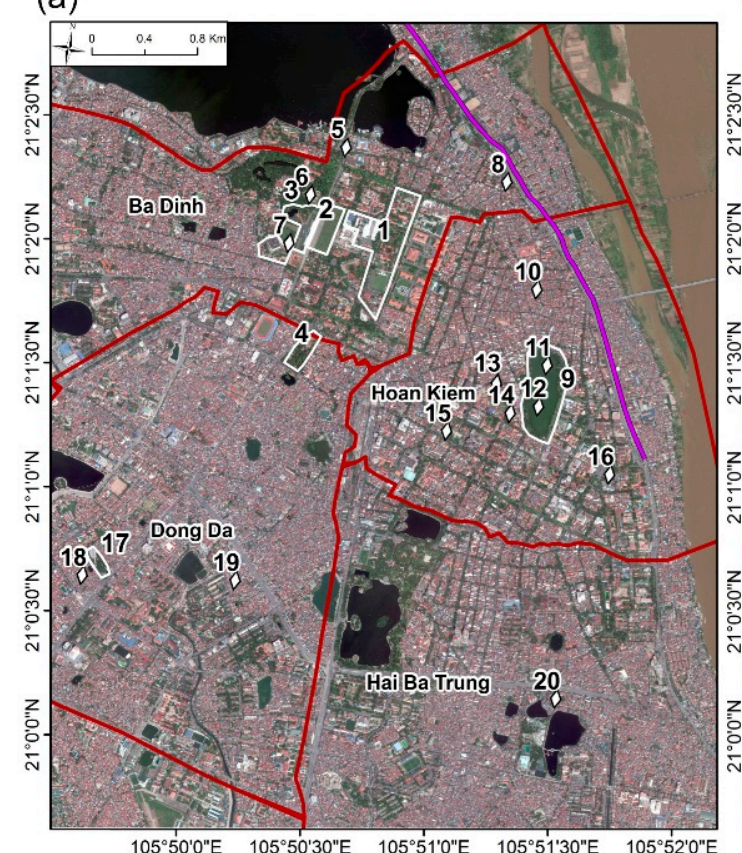

(b)

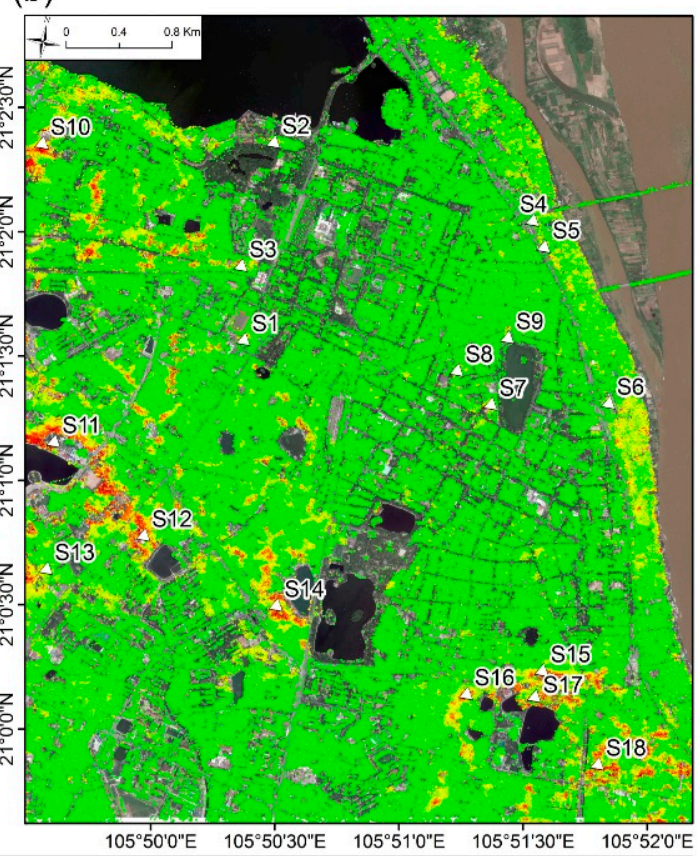

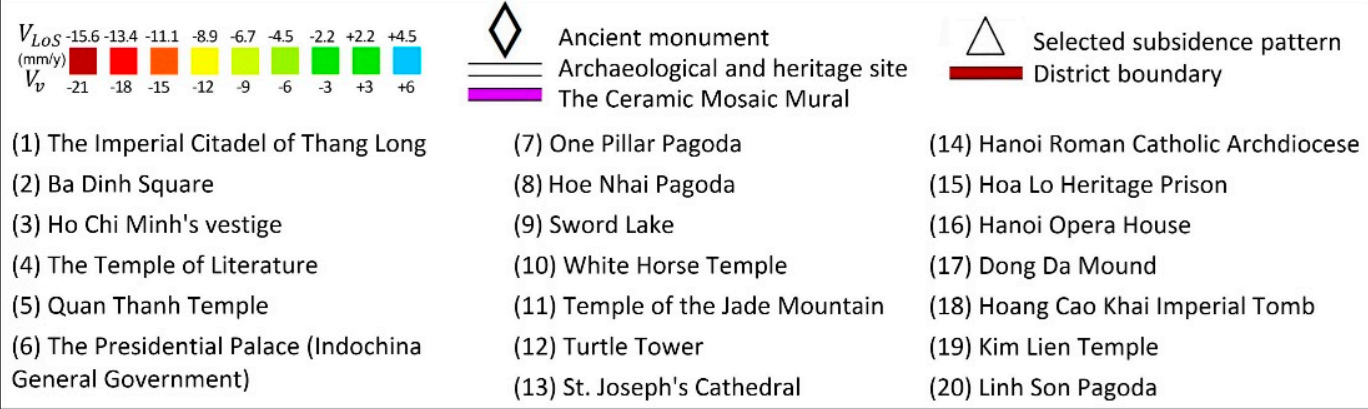

Figure 4. (a) An optical satellite image acquired in September 2012 (provided by Google Earth) represents the location of historical relics, archaeological ruins and ancient monuments in Hanoi Historical Centre; (b) Average for April 2012-November 2013. Line-of-Sight (LoS) velocity map of Hanoi Historical Centre. Mean LoS and projected vertical velocity are in $\mathrm{mm} /$ year. Selected subsidence patterns are labelled from S1-S18.

In this study, we used aerial images taken in July 2010, which were provided by Bing Maps ( Microsoft). All other satellite images were provided by Google Earth for the time from 2012 to the end of 2013. The distances from the center of the subsidence bowls, derived from InSAR observation, to the nearest construction sectors were measured. The construction sectors were chosen based on the urban land cover map provided by Hanoi Environment and Natural Resources Department (Figure 5) and visual interpretation based on time-series Google Earth images. Only large building sites and urban re-planning areas, which have high potential to influence the stability of the ground, were taken into account. 


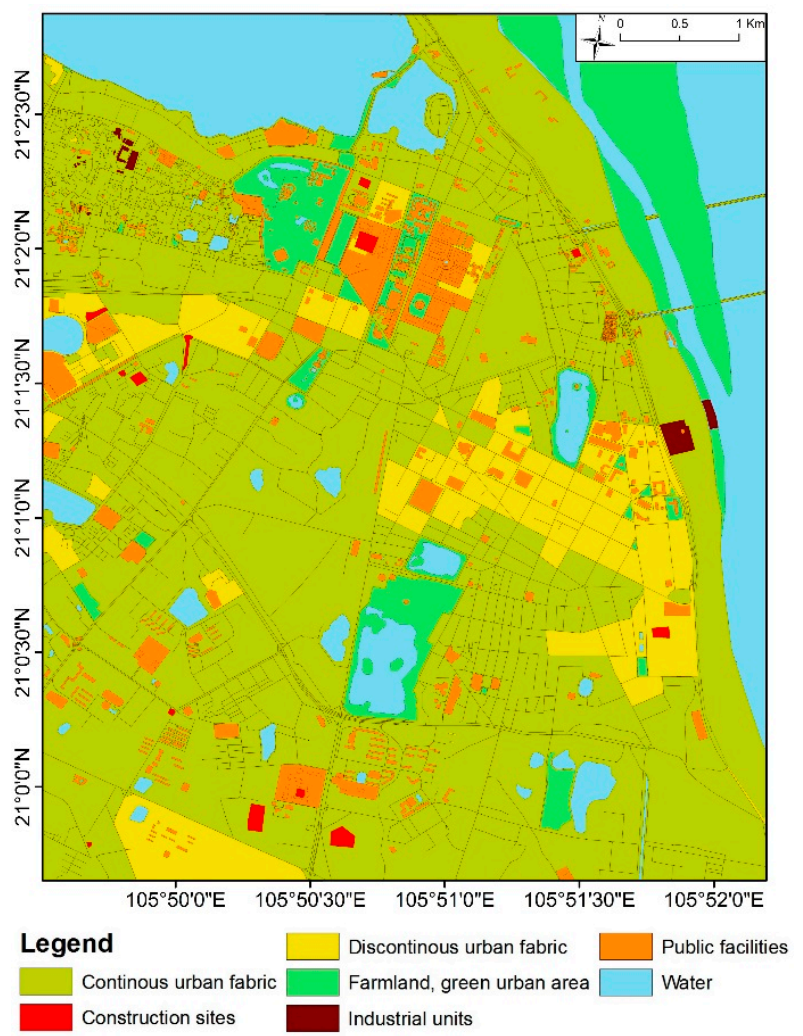

Figure 5. Land cover map of the Historical Centre of Hanoi, provided by Hanoi Environment and Natural Resources Department.

\subsubsection{The Citadel}

In general, heritage culture sites and ancient monuments in this area, labelled as 1-7 (in Figure 4), are stable with an average subsidence rate typically lower than $-3 \mathrm{~mm} /$ year. The highest rate over those sites was recorded at the Temple of Literature, which suffers an average subsidence velocity of $-2.6 \mathrm{~mm} /$ year.

SDFP density observed in Imperial Citadel of Thang Long, Ho Chi Minh's vestige and the Temple of Literature are $102,044,108,654$ and $60,047 \mathrm{SDFP} / \mathrm{km}^{2}$, respectively. Those densities are significantly lower than those observed from the adjacent residential areas located nearby. It is due to the fact that the vegetation coverage was maintained during the study period, especially at the Temple of Literature and a new archaeological excavation area of Imperial Citadel of Thang Long discovered in 2004. Furthermore, with a relatively short wavelength of $3.1 \mathrm{~cm}$, the capability of penetrating the canopy of the X-band microwave signal is limited. Therefore, the coherence in those areas could not be preserved.

After comparing with the surface geology map of the study site (Figure 1), we found that the monuments and archaeological sites in this area are located on clay sediments, which is less compressible compared to other soil types in the study area. The shape of subsidence patterns observed in this area are relatively small and clustered. Three notable patterns were observed in the residential areas of Hang Chao (S1-Figure 6a), Thuy Khue (S2-Figure 6b) and Le Hong Phong (S3-Figure 6c). Thanks to the high density of SDFP obtained in those areas which are 67,548, 215,248 and $312,500 \mathrm{SDFP} / \mathrm{km}^{2}$, respectively, subsidence patterns of those three subsidence sites can be clearly located. The temporal evolution charts show a relatively similar trend: the mean subsidence velocities of observed SDFP surprisingly decrease during a short period of time, from May to July-August 2012. The reason could be considered as the abrupt decline of groundwater at the local level but at an extensive volume in a short span of time. 


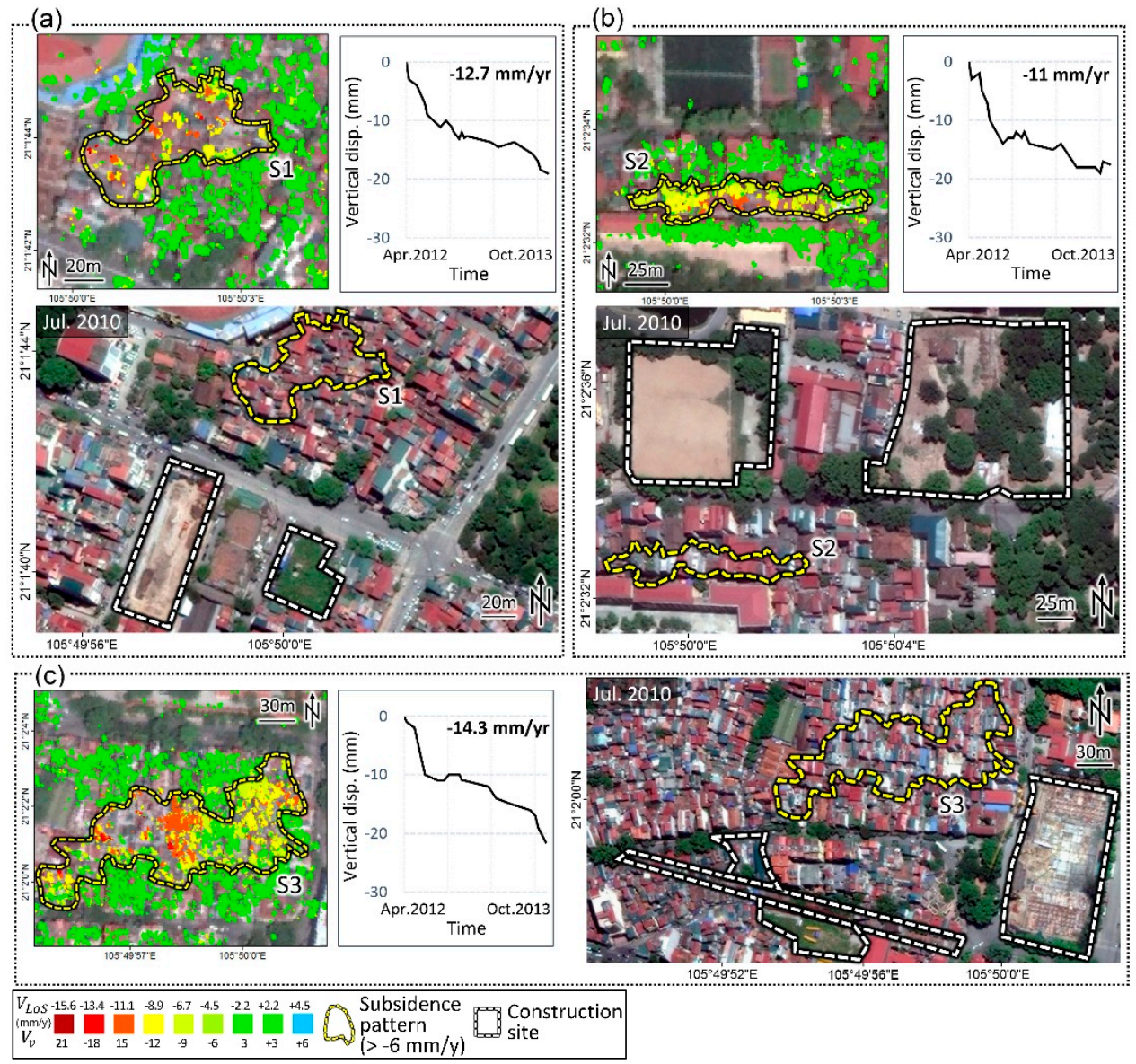

Figure 6. Average for April 2012-November 2013. LoS velocity map, temporal evolution chart and optical image represent location of subsidence pattern and construction sites in (a) Hang Chao (S1), (b) Thuy Khue (S2) and (c) Le Hong Phong (S3). Characters in parentheses denote the label of subsidence patterns in Figure 4.

We relied on aerial and satellite optical images to trace the causes of observed subsidence patterns. Aerial images in Figure 6b, which were captured in July 2010, show that the subsidence pattern observed in Thuy Khue was located in the adjacent building blocks 17-17G. The subsidence center was detected at buildings number 17E and 17F. We found that the distance from the subsidence center to the nearest construction sites is $36 \mathrm{~m}$. Therefore, the cause of this pattern is considered to be the result of massive water pumping for construction purposes, because construction water extraction in Hanoi typically uses underground boreholes built in the center of the residential area, which were specifically constructed for domestic water extraction.

Additionally, optical images in Figure $6 a, c$ indicated the same things happened with the subsidence patterns located in Hang Chao (S1) and Le Hong Phong (S3). The distance between subsidence centers in Hang Chao, Le Hong Phong and the nearest construction sites are $95 \mathrm{~m}$ and $104 \mathrm{~m}$, respectively. In particular, those patterns are relatively close to the heritage and culture sites, about $97 \mathrm{~m}$ and $78 \mathrm{~m}$ away from Ho Chi Minh's vestige and the Temple of Literature, respectively. Therefore, those patterns could possibly affect the stability of heritage sites mentioned above, if the subsidence driving factors continue.

\subsubsection{Monuments on the Red River Bank}

Unlike monuments in the Citadel, those located on the Red River bank are entirely on sand sediments enriched by the Red River. Due to the high compressibility of sandy soil, subsidence 
patterns observed in this area were widely distributed; a reference number is a $0.17 \mathrm{~km}^{2}$-large pattern depicted in the South of Hanoi Ceramic Mosaic Mural (S6-Figure 7c). Thus, subsidence in this area is more likely to be influenced by the soft soil properties with the aid of anthropogenic activities, instead of only massive groundwater pumping.

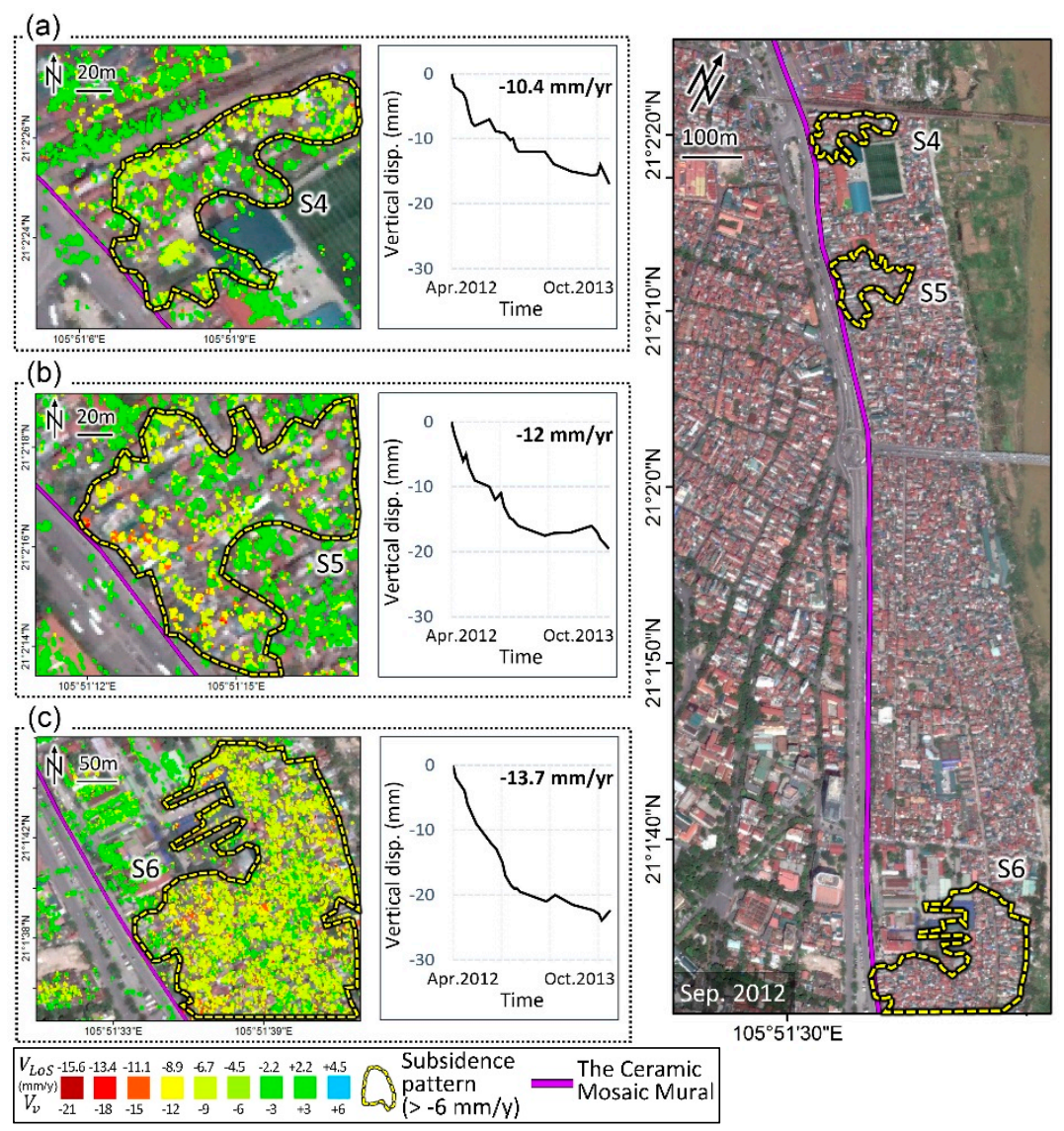

Figure 7. Average from April 2012-November 2013. LoS velocity map, temporal evolution chart and optical image represent location of subsidence pattern in (a) Phuc Tan 1 (S4), (b) Phuc Tan 2 (S5) and (c) Hong Ha (S6). Characters in parentheses denote the label of subsidence patterns in Figure 4.

Due to the fact that soil in this area mainly consists of sand, subsidence patterns lead to lower local ground and a high water table could be brought by water recharge of the Red River. Moreover, buildings and structures located in subsidence patterns observed in the Red River bank could be potentially damaged or destroyed by a moderate earthquake. This is mostly due to soil liquefaction, which is described as the loss of shear resistance and soil coherence due to high water table during shock loading $[33,34]$. The soil could be subject to large deformation during dynamic stress if its shear resistant become less than static [35]. In short, if earthquakes occur in this area, subsidence areas observed by TerraSAR-X data could be significantly damaged.

We assessed the condition of three heritage sites and monuments: Hoe Nhai Pagoda, White Horse Temple and Hanoi Ceramic Mosaic Mural. Located on wide range of subsidence patterns, Hoe Nhai Pagoda and White Horse Temple have the average subsidence rates of -4.8 and $-5.3 \mathrm{~mm} /$ year with the maximum subsidence observed as -7.5 and $-8.5 \mathrm{~mm} /$ year, respectively. A total of 41 SDFP were observed for Hoe Nhai Pagoda and 142 for White Horse Temple, maintaining the comprehensive monitoring capability for those monuments.

Hanoi Ceramic Mosaic Mural, which was constructed in 2007 on the occasion of the Millennial Anniversary of Hanoi, is a $3.85 \mathrm{~km}$ length linear modern monument. Located on the ground of soft soil 
along the Red River, there were subsidence bowls cut across the monuments, as depicted in Figure 7. We analyzed the InSAR-derived result for 21,801 SDFP observed along the monument with a deviated radius of $2 \mathrm{~m}$. The mean subsidence rate is $-6 \mathrm{~mm} /$ year; however, the maximum reaches up to $-18.3 \mathrm{~mm} /$ year. We localized the subsidence patterns in three areas, where cracks and deterioration have been reported by public media.

Three noticeable subsidence areas in Phuc Tan 1 (S4-Figure 7a), Phuc Tan 2 (S5-Figure 7b) and Hong Ha (S6-Figure 7c) are observed. Figure 7a shows that the subsidence pattern in Phuc Tan 1 scattered along Long Bien bridgehead and the pavement building blocks of Tran Nhat Duat street. The mean subsidence velocity observed in this area is $-10.4 \mathrm{~mm}$ /year with the average temporal evolution represented in Figure 7a, showing a linear subsiding trend. Figure $7 \mathrm{~b}$ focused on the subsidence pattern in pavement building blocks along Tran Nhat Duat street. Subsidence in this area is mainly spread on the pavement building blocks numbered 113 to 121 with the average rate of $-12 \mathrm{~mm}$ /year; the inner blocks are relatively stable.

The subsidence patterns observed in Hong Ha (S6-Figure 7c) are located on a large area along the riverbank. Here we detected the highest mean subsidence rate along the Hanoi Ceramic Mosaic Mural as $-13.7 \mathrm{~mm}$ /year. According to the land cover map provided by Hanoi Environment and Natural Resources Department (Figure 5), an industrial area was found in the center of this subsidence pattern. Although no sign of a large construction site was detected, we could corroborate the hypothesis that is raised below: the causes and characteristics of land subsidence in this area are mainly due to the combination of soft sediments and anthropogenic processes.

\subsubsection{The Old Quarter and French Quarter}

The Old Quarter and the French Quarter are the most densely populated areas in Hanoi city. The Old Quarter, which is generally known as 36 Ancient Streets, comprises buildings and monuments built in the 1870s. They are characterized by a narrow (3 to $4 \mathrm{~m}$ ) and long (40 to $60 \mathrm{~m}$ ) shape [36], rendering them more susceptible to vertical ground displacement. On the other hand, the French Quarter includes newer buildings planned block by block. Taking advantage of the $3 \mathrm{~m}$ resolution of TerraSAR-X images and oversampling implementation, we observed 530,795 SDFP for the whole area, preserving a mean SDFP density of 296,382 SDFP $/ \mathrm{km}^{2}$. This density enables the measure and interpretation of land subsidence at the level of detail of a single building and monument. We analyzed SDFP first on heritage sites and ancient monuments, taking into account noticeable subsidence patterns that could potentially influence the stability of neighboring buildings and structures.

Eight ancient buildings and heritage sites are selected for further analysis in the Old Quarter and the French Quarter. They are numbered by 9 for Sword Lake and 11-16 for prevailing ancient constructions (Figure 4). Monuments included in the Sword Lake site are classified as stable sites, namely Sword Lake, Temple of the Jade Mountain and Turtle Tower. The mean subsidence rate of Temple of the Jade Mountain and Turtle Tower are -2.2 and $-2.7 \mathrm{~mm} /$ year, respectively. There are 31 SDFP observed over Turtle Tower, representing $28.4 \mathrm{~m}^{2}$ surface of the tower only, although it is located on a $350 \mathrm{~m}^{2}$ mound. This implies that one measurement point for every square meter can be achieved for a single small monument. This density enables the observation of deterioration in even a corner of a building, provided it is large enough. On the other hand, the average subsidence rate of 9141 SDFP observed over Sword Lake is $-4.2 \mathrm{~mm} /$ year. Despite being classified as fairly stable, this value is affected by rapid sinking SDFP detected in the north and the west of the site. These SDFP pixels belong to the subsidence bowls with the centers located outside the site, which are discussed in the following paragraphs.

Only Hoa Lo Heritage Prison is in a stable condition, with an average subsidence value of 90 SDFP at $1.6 \mathrm{~mm}$ /year. The remaining heritage buildings and monuments affected by neighboring subsidence patterns include St. Joseph's Cathedral, Hanoi Roman Catholic Archdiocese and Hanoi Opera House. We counted 1793 SDFP for Hanoi Opera House, which experiences an average subsidence rate of $-3.8 \mathrm{~mm}$ /year. On the contrary, the subsidence in St. Joseph's Cathedral and Hanoi Roman Catholic 
Archdiocese are considered to be impacted by construction activities and groundwater extraction. The shape of those subsidence sectors are uniquely observed as small and rapid patterns. The average level of subsidence of St. Joseph's Cathedral and the Roman Catholic Archdiocese of Hanoi are -4.3 and $-10 \mathrm{~mm} /$ year, respectively.

Subsidence patterns that influence the instabilities of Hanoi Roman Catholic Archdiocese and St. Joseph's Cathedral are triggered by the subsidence centers observed in Hang Trong (S7-Figure 8a) and Tho Xuong (S8-Figure 8b), respectively. Hang Trong, which has the average subsidence rate of $-14.2 \mathrm{~mm} /$ year, is located next to a major construction area including skyscrapers and other high-rise buildings. The distance from the subsidence center to Hanoi Roman Catholic Archdiocese is only $12 \mathrm{~m}$, as is evident in the optical satellite image taken in September 2012 (Figure 8a), thereby explaining the abnormal subsidence recorded for this cultural monument and surrounding infrastructure.

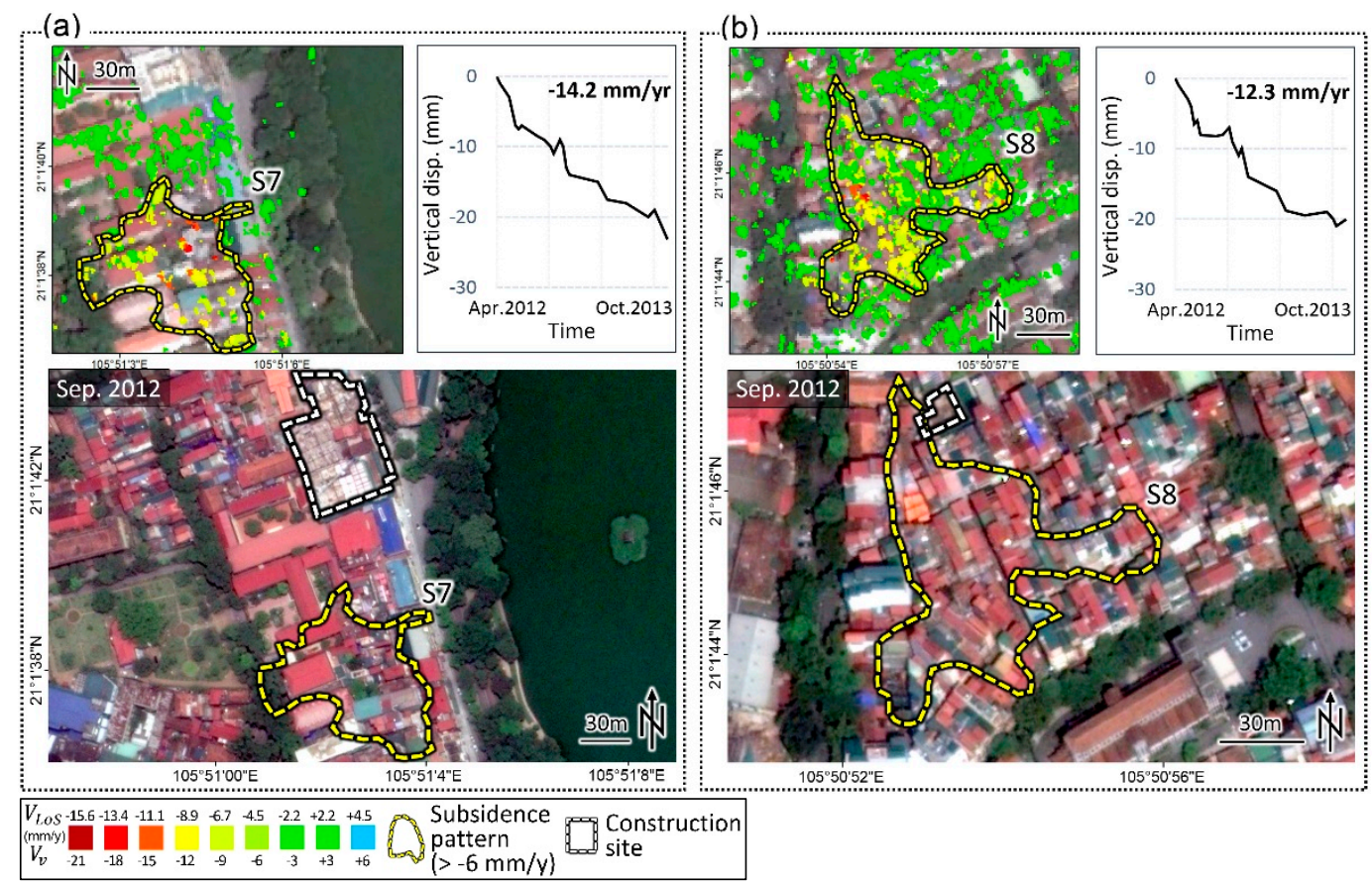

Figure 8. Average for April 2012-November2013. LoS velocity map, temporal evolution chart and optical image represent location of subsidence pattern and construction sites in (a) Hang Trong (S7) and (b) Tho Xuong (S8). Characters in parentheses denote the label of subsidence patterns in Figure 4.

\subsubsection{Prevailing Subsidence Patterns}

There are not many ancient monuments and heritage assets situated in the southern quarters of Hanoi: Dong Da Mound, Hoang Cao Khai Imperial Tomb, Kim Lien Temple and Linh Son Pagoda, which are numbered 17-20, respectively (Figure 4). In general, they are all affected by subsidence bowls located nearby. Only Kim Lien Temple is considered stable with a subsidence rate of $-2.5 \mathrm{~mm} /$ year; the two neighboring historical sites, Dong Da Mound and Hoang Cao Khai Imperial Tomb, suffer from subsidence velocities of -5.7 and $-6.5 \mathrm{~mm} /$ year. Similar to the case of the Temple of Literature that is discussed in Section 5.1.1, high vegetation cover over Dong Da Mound causes temporal decorrelation, leading to a lower SDFP density of about $85,558 \mathrm{SDFP} / \mathrm{km}^{2}$, as compared to the mean density of 217,012 SDFP $/ \mathrm{km}^{2}$. Subsidence bowls observed in the south of Hoang Cao Khai Imperial Tomb are considered to be the main causes of subsidence phenomena for both these two sites. The higher subsidence level of Hoang Cao Khai Imperial Tomb in comparison to Dong Da Mound is due to the following two reasons: (1) The distance from Dong Da Mound to subsidence patterns is farther than from Hoang Cao Khai Imperial Tomb; (2) Hoang Cao Khai Imperial Tomb is entirely located in a 
densely populated area, where construction and groundwater extraction activities often take place, causing the instability of the surface.

Over Linh Son Pagoda, 129 SDFP are detected with the average subsidence value of $-14.8 \mathrm{~mm}$ /year. The maximum subsidence velocity reached $-18.5 \mathrm{~mm} /$ year, but there are no large construction sites found near those patterns.

Subsidence patterns influenced by construction processes are Lieu Giai (S10-Figure 9a) and Dong $\mathrm{Da}$ (S11-Figure 9b). The distance from these structures to the nearest construction sites are $17 \mathrm{~m}$ and $1 \mathrm{~m}$, respectively. We experienced difficulties in determining the subsidence center in Dong Da due to the lack of SDFP for the main construction site. This was induced by the surface changes resulting in loss of coherence, as experienced in the case of sites with high vegetative coverage. The optical image taken in November 2013 (Figure 9b) revealed large construction processes observed in the center of the subsiding area. SDFP with high subsidence rate were detected around the site with the average value reaching $-15.7 \mathrm{~mm} /$ year. Note that the new high-rise buildings nearby are represented by stable SDFP. This implies the subsidence patterns in this area are only involved through the consequences of construction activities instead of massive groundwater pumping, as observed in many areas with construction processes. This interpretation is based on the fact that the subsidence patterns only appear around the construction area and do not affect the stability of new high-rise buildings, which are known for more solid foundation structure as compared to other civilian buildings.

The subsidence center in Lieu Giai (S10-Figure 9a) is located at the center of adjacent residential areas instead of around a construction area, which is similar to the cases recorded and discussed in Section 5.1.1. The average subsidence rate reaches $-16.8 \mathrm{~mm} /$ year. The temporal evolution chart (Figure 9a) indicates that in the linear trend of observed SDFP, no recovery signal is detected. Besides, the subsidence patterns around the construction zones are also observed, though they are is not as severe (see the optical image in Figure 9a). Another factor that is worth considering is the use of groundwater for domestic purposes and for the sports complex nearby.

We took into account two subsidence areas which have a high rate and are widely distributed (Kim Hoa: S12-Figure 9c) thus directly affecting the historical sites (Thai Ha: S13-Figure 9d). Large construction sites, comprised of high-rise buildings and large structures, were simultaneously built in the period from 2010 to 2013 next to the subsidence center in Kim Hoa (S12-Figure 9c). The subsidence center is only $6 \mathrm{~m}$ away from the construction site. The mean deformation rate is observed as $-17.9 \mathrm{~mm} /$ year. The temporal evolution chart (Figure 9c) indicates a substantial downward trend from June-December, 2012 that slows for the remaining period. The shape of subsidence patterns in this area are sharp with high magnitude, which thus potentially threaten surrounding buildings and structures.

Similarly, we found a high-rise building construction sector which only $21 \mathrm{~m}$ away from the subsidence center observed in Thai Ha (S14-Figure 9d). The rate of subsidence is a $-6 \mathrm{~mm} /$ year downward trend that tends to recover in September 2013. However, this wide subsidence pattern is considered as the main cause affecting the stability of Hoang Cao Khai Imperial Tomb and Dong Da Mound. Compared to the surface geology map (Figure 1), the ground of this area is formed by highly compressible loamy sand sediments. Additionally, the southern and western areas of Hanoi are known as the location of ancient rivers. Therefore, subsidence patterns observed in this area are wider and at a higher magnitude than those observed in the north of the study area.

Although not affected by water recharge from the Red River, subsidence patterns in southwestern Hanoi could be influenced by the soil liquefaction phenomenon due to the characteristics discussed above. When an earthquake occurs in an area with buildings that have previously been damaged by a high rate of subsidence over time, the level of damage that could be more serious than along the Red River bank, especially in centers of high-rate subsidence patterns near large construction sites. 

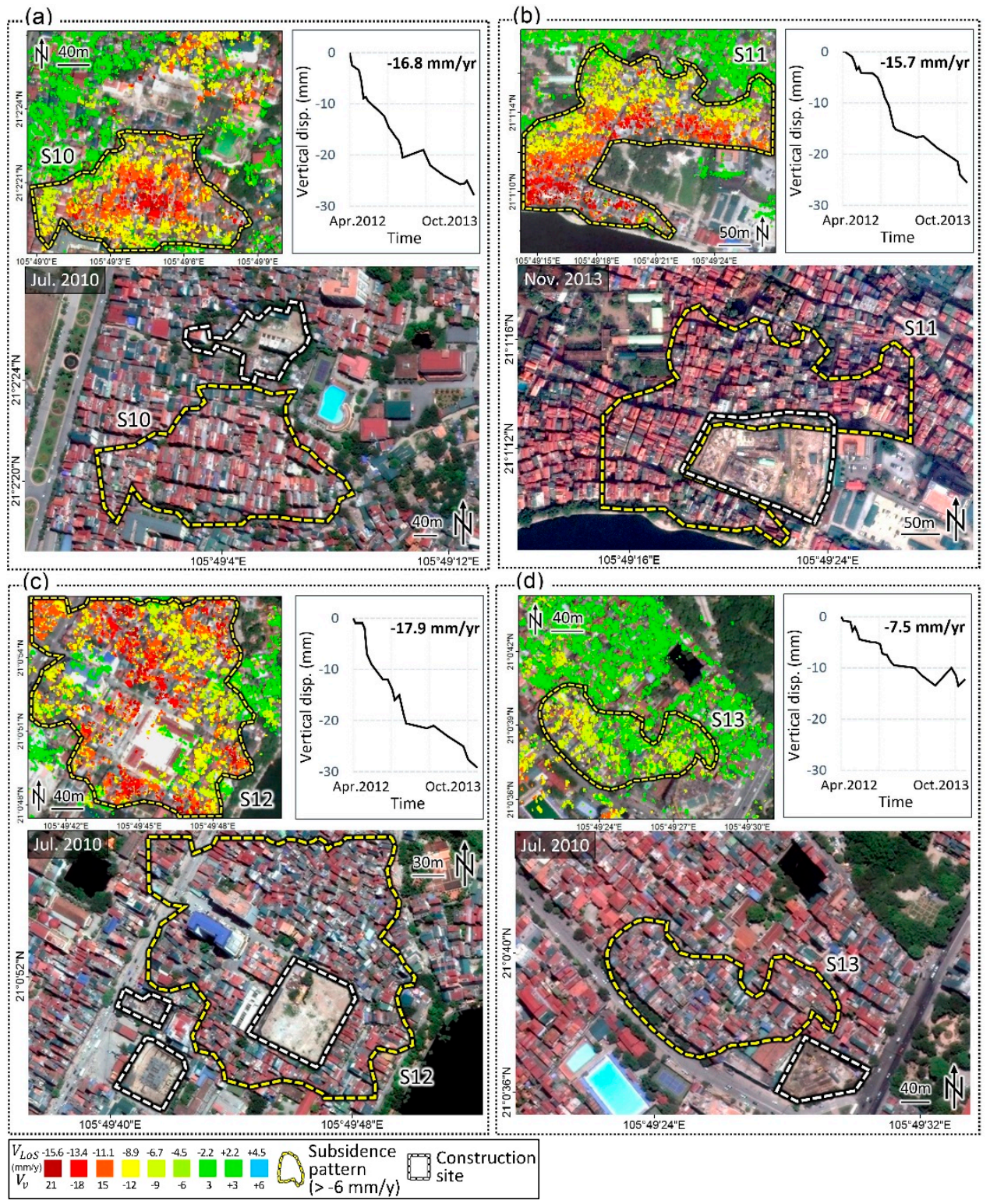

Figure 9. Average for April 2012-November 2013. LoS velocity map, temporal evolution chart and optical image represent location of subsidence pattern and construction sites in (a) Lieu Giai (S10); (b) Dong Da (S11); (c) Kim Hoa (S12) and (d) Thai Ha (S13). Characters in parentheses denote the label of subsidence patterns in Figure 4.

\subsection{Oversampling Influence on SB InSAR Processing}

The efficiency of image oversampling implementation was evaluated by examining the spatial distribution and quantitatively analyzing the SDFP derived both with and without image oversampling. Different testing methods, including phase noise estimation and density evaluation, were carried out to assess the efficiency and rationality of new SDFP generated after integrating image oversampling.

\subsubsection{Spatial and Coherence Distribution of Slowly Decorrelating Filtered Phase (SDFP) Pixels}

Figure 10a,b show the spatial distribution of SDFP obtained with and without oversampling for the entire study area, respectively. In total, 1.4 million SDFP were generated by the standard SB InSAR processing chain. After applying image oversampling, 6.29 million SDFP are counted. The SDFP oversampled dataset maintains a high SDFP density over $28.9 \mathrm{~km}^{2}$ of our study area: 
217,012 SDFP $/ \mathrm{km}^{2}, 4.4$ times more than those derived without oversampling implementation: 49,248 SDFP $/ \mathrm{km}^{2}$. As expected, the increment of SDFP impacted the subsidence assessments of the area in two ways, by: (1) Providing the capability to monitor the subsidence processes in a higher level of detail; and (2) Enlarging the monitoring coverage, especially in areas with fewer SDFP, e.g., Ba Dinh Square or Thang Long Bridge.

(a)
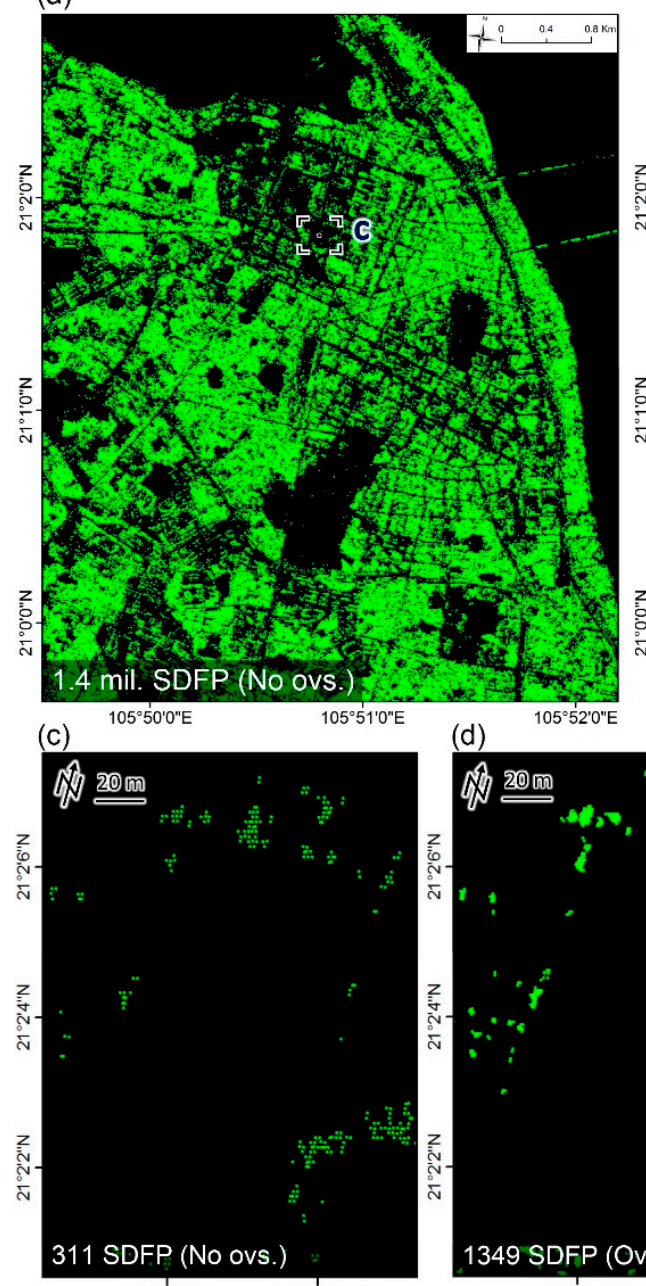

105050'26"E $\quad 105^{\circ} 50^{\circ} 28^{\prime \prime} \mathrm{E}$

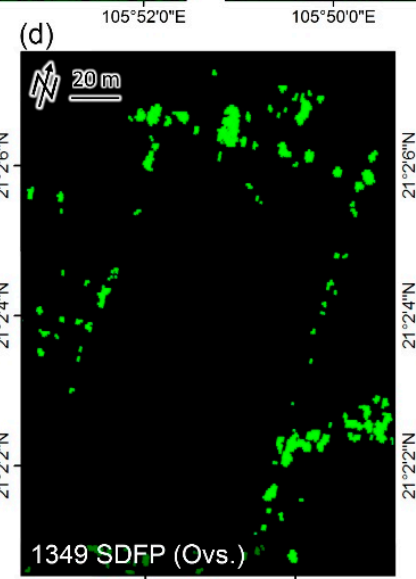

10550'26"E $105^{\circ} 50^{\circ} 28^{\prime \prime} \mathrm{E}$
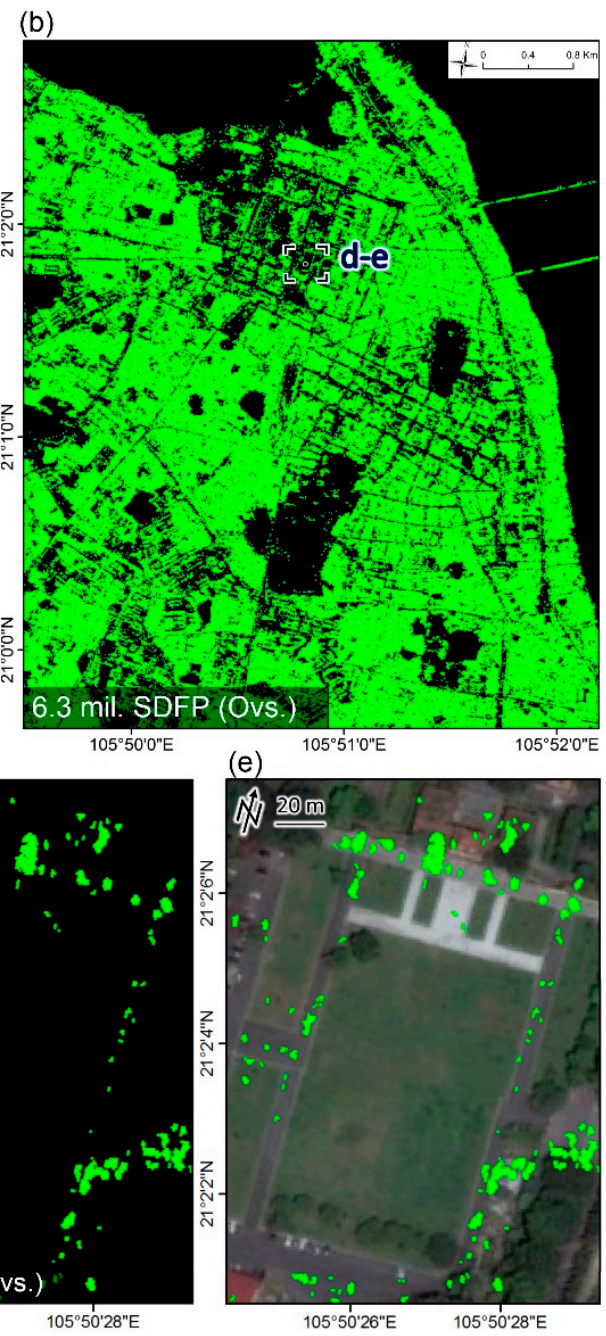

Figure 10. Binary images represent the spatial distribution of SDFP over study area derived by (a) normal TerraSAR-X data and (b) oversampled data. Enlarged SDFP location in Flag Pole Stadium for the data (c) without oversampling; (d) with oversampling and (e) with oversampling projected onto an optical image.

Prominent benefits of image oversampling over SB InSAR processing are the relocation of pixel centers and the ability to determine the SAR coordinate at sub-pixel level, as discussed in Section 4.1. To confirm the hypotheses, it is worth testing the origin of newly formed SDFP after applying image oversampling. We focused on Flag Pole stadium, a small heritage venue located in Ba Dinh Square. There had been relatively sparse SDFP distribution over this site, but after the image oversampling, we could clearly detect the newly formed SDFP patterns.

Figure 10c,d represent SDFP distribution for the same area of Flag Pole stadium, without and with oversampling implementation, respectively. There are 331 SDFP observed for the normal data and 1349 SDFP for the oversampled TerraSAR-X data. We found that the newly formed SDFP are not only influenced by the same pixels as existing SDFP, but also from new pixels, generating new SDFP 
patterns. Since it is important to trace the origin of the newly formed SDFP patterns, we projected SDFP generated by the oversampled dataset to an optical satellite image, which was captured in September 2012 (Figure 10c). The result shows a good fit of newly formed SDFP patterns, especially linear ones, to straight roads around the greensward. This example suggests that the oversampling implementation not only enhances the detail in subsidence monitoring but also expands the coverage, which are essential when using the standard processing chain.

On the other hand, the coherence values for every individual SDFP were calculated and presented as an overlapped histogram (Figure 11a). Sousa et al., [19] applied this test for the PSI method to determine whether the increment of SDFP after oversampling is contributed by adding noisier SDFP to the result or not. Overall, significant degradation in coherence was not observed from the oversampled dataset. This observation confirms the same trend as the oversampled PSI dataset tested by Sousa et al., [19]. Moreover, the differences lay on SDFP with the coherence value less than 0.7. After applying oversampling, SDFP with a coherence value less than 0.7 are significantly reduced, which does not happen with the normal dataset. Figure $11 \mathrm{~b}$ clearly shows this phenomenon. Although the peaks of coherence are at 0.92 for both oversampled and not oversampled datasets, the number of SDFP observed with oversampling was less than that obtained without oversampling, for the coherence range $0.4-0.6183$. However, it is worth noting that oversampling could not enhance the overall coherence of observed SDFP. For coherence value of about $0.7-0.9$, noisier pixels were broadly added after applying oversampling.

(a)

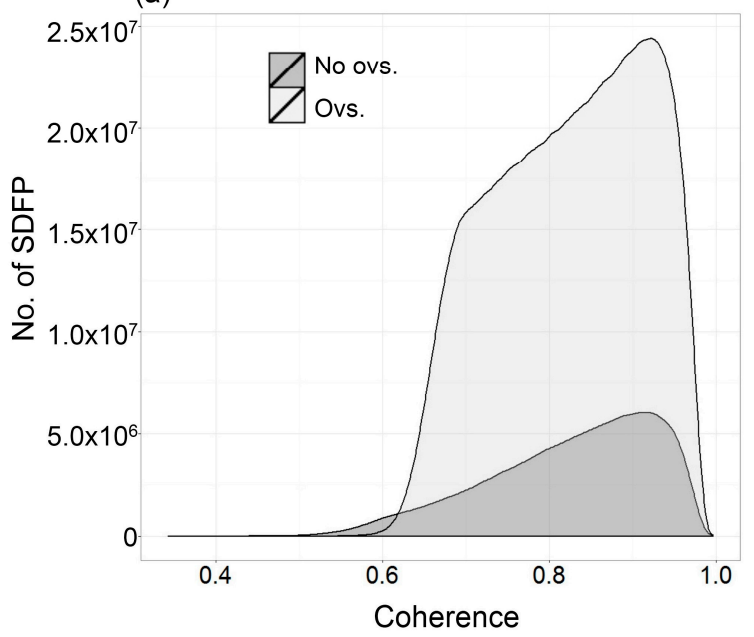

(b)

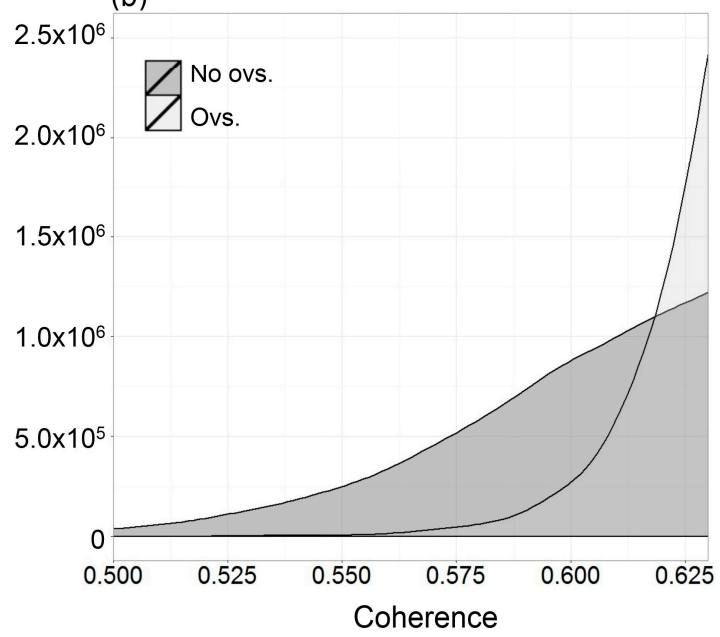

Figure 11. (a) Overlapped histogram of coherence distribution for all observed SDFP; (b) Histogram with adjusted visible coherence range of 0.5-0.63.

The cause behind the reduction of the low-coherence-pixel observed in the InSAR result (clearly shown in Figure 11b) impact oversampling on the co-registration precision, as discussed in Section 4.1. The coordinate of radar signal could be detected at the sub-pixel level with oversampling implemented. Therefore, interferometric pairs are better co-registered with the same parameters. This leads to the increment of total coherence in each pair, resulting in higher value of coherence observed in SDFP time-series.

\subsubsection{SDFP Density}

In order to calculate the SDFP density as well as measure the increment after applying oversampling over different land cover classes, we used a 1:10,000 land cover map provided by Hanoi Environment and Natural Resources Department (Figure 5). The map divides the area of Hanoi Historical Centre into seven urban classes, including continuous urban fabric, discontinuous urban fabric, construction sites, green urban area, industrial units, public facilities and water bodies. SDFP 
number and density for both normal and oversampled TerraSAR-X datasets are counted for every land cover class and summed up in Table 1. Only those SDFP that were entirely located in a land cover class were taken into account. Those located on the boundary between two classes are eliminated in order to minimize the georeferencing error between land cover map and InSAR-derived SDFP.

Table 1. Number and density of SDFP observed over 7 land cover classes.

\begin{tabular}{|c|c|c|c|c|c|}
\hline Land Cover Class & $\begin{array}{c}\text { No. SDFP } \\
\text { (No ovs.) }\end{array}$ & $\begin{array}{c}\text { No. SDFP } \\
\text { (Ovs.) }\end{array}$ & $\begin{array}{c}\text { Land Cover } \\
\text { Class Coverage } \\
\left(\mathbf{k m}^{2}\right)\end{array}$ & $\begin{array}{l}\text { SDFP Density } \\
\text { without ovs. } \\
\left(\mathrm{SDFP} / \mathrm{km}^{2}\right)\end{array}$ & $\begin{array}{c}\text { SDFP Density } \\
\text { with Ovs. } \\
\left(\mathrm{SDFP} / \mathrm{km}^{2}\right)\end{array}$ \\
\hline Continuous urban fabric & 747,578 & $3,313,949$ & 17.19 & 43,480 & 192,743 \\
\hline Discontinuous urban fabric & 73,116 & 325,172 & 2.82 & 25,947 & 115,396 \\
\hline Construction sites & 150 & 672 & 0.09 & 1659 & 7434 \\
\hline Green urban areas & 5089 & 18,077 & 2.38 & 2135 & 7584 \\
\hline Industrial units & 1613 & 6775 & 0.07 & 23,874 & 100,279 \\
\hline Public facilities & 18,014 & 78,361 & 1.82 & 9880 & 42,979 \\
\hline Water bodies & 479 & 2119 & 4.60 & 104 & 460 \\
\hline
\end{tabular}

SDFP were distributed unevenly between different land cover classes. As expected, a large number of SDFP was counted in the area of continuous urban fabric: 747,578 and 3,313,949 for normal and oversampled TerraSAR-X data, maintaining the highest SDFP density over land cover classes: 43,480 and 192,743 SDFP/ $\mathrm{km}^{2}$ without and with oversampling implemented, respectively. Considering the SDFP result obtained without oversampling implementation, SDFP density decreased with respect to the land cover classes. The observed SDFP density without oversampling for continuous urban fabric, discontinuous urban fabric, industrial units, public facilities, green urban area and water bodies are: 43,$480 ; 25,947 ; 23,874 ; 9880 ; 2135 ; 1659$; and $104 \mathrm{SDFP} / \mathrm{km}^{2}$, respectively.

A significant contrast between the fixed surface (urban fabric, industrial and public units) and the surface tends to change over time (water bodies, vegetative and construction areas), as illustrated by observed SDFP densities. Comparing with previous results from Cigna et al., [37], SDFP density for the water class is relatively high: $104 \mathrm{SDFP} / \mathrm{km}^{2}$ without oversampling and $460 \mathrm{SDFP} / \mathrm{km}^{2}$ with oversampling implementation. Four driving factors are taken into account: (1) The high phase noise of SDFP and the uncertainty in SB InSAR processing, especially common in longer wavelengths, is often not sensitive enough for small-scale deformation. Moreover, the limited SAR acquisitions are more likely to misclassify the displacements that are influenced by noise and actual deformation [21]; (2) The aforementioned georeferencing error between land cover maps and derived SDFP results, even if only a few meters off, may induce the misclassification of thousands of SDFP; (3) As a consequence of the inaccuracy and low resolution of land cover class, precision at sub-meter and the visibility of small objects (e.g., a pile of debris, small construction site on water) cannot be maintained. This leads to error since the high-density SDFP may appear over those objects, thereby increasing the likelihood of their being misclassified as water. Additionally, the original date of the map could not be confirmed. Therefore, certain discrepancies are expected due to the temporal changes between land cover classes; (4) The overall SDFP density observed in this study is 77 times higher than the density observed by Cigna et al., [37], whereas the SDFP density on water in our work is only 4.9 times more, implying the relative ratios shown in our work to be more rational.

Regarding the SDFP density over seven land cover classes generated with and without oversampling, significant improvements were found. Taking the continuous urban fabric class into consideration, the observed SDFP with oversampling implementation are 192,743 SDFP $/ \mathrm{km}^{2}$ and 43,480 SDFP $/ \mathrm{km}^{2}$ without oversampling, equaling 4.3 times less. The increment ratios are $4.45,4.48$, $3.55,4.2,4.35$ and 4.42 for discontinuous urban fabric, industrial units, public facilities, green urban areas and water bodies, respectively. We found that one exception is the increment ratio of 3.55 for the construction site category, while other classes showed the similarity in increment ratio, ranging from 4.2 to 4.88 . The results differ from those that pointed out by Sousa et al., [19] with PSI procedure, whose 
increment ratio was calculated for different crops classified by visual interpretation. In our work, the relative consistency of the increment ratios was found between different classes. This could be because of the differences between the two processing chains, the influence of terrain and the differences in wavelengths between the two studies. However, with 6.29 million measurement points over $28.9 \mathrm{~km}^{2}$ of the study area, significant improvements were recorded in both detail and coverage aspects as compared to previous studies.

\section{Conclusions}

This paper presents the distribution and evolution of recent subsidence patterns detected in the Historical Centre of Hanoi, Vietnam in the period from April 2012-November 2013 by processing 23 TerraSAR-X images using StaMPS (Stanford Method for Persistent Scatterer) SB (small baseline) InSAR (Interferometric Synthetic Aperture Radar) approach. To achieve higher coverage and a better level of detail, image oversampling was implemented into SB InSAR processing chain for the first time. A remarkably high SDFP (slowly decorrelating filter phase) pixel density was recorded: an average of $217,012 \mathrm{SDFP} / \mathrm{km}^{2}$, which is 4.4 times more than the density recorded without oversampling implementation. This allows for an assessment of the condition of a single building or monument, which is in turn essential for subsidence monitoring of cultural heritage buildings, monuments and sites.

The characteristics of 18 subsidence patterns and their impacts on the stability of 21 cultural heritage sites was discussed. Patterns found along the Red River and in southern quarters are widely distributed and have a high rate of velocity, up to $-18.1 \mathrm{~mm} /$ year. In many locations it was found that the subsidence areas are correlated with nearby construction sites. The distance from subsidence centers to the nearest construction sites is typically below $100 \mathrm{~m}$. The composition of different sediment types also affect the level of subsidence phenomena. Subsidence patterns observed along the Red River and in southwestern Hanoi, which are comprised of sand and loamy sand, are easily affected by anthropogenic activities. Thus, they not only tend to occur at a high rate and are widely distributed, but they are also subject to ground cohesion damage. This could potentially lead to infrastructure destruction due to soil liquefaction when a high water table and dynamic motion occur at the same time.

Further work should be carried out by applying image oversampling to new images from TerraSAR-X and newly launched sensors to evaluate the performance of oversampling at different sensors and wavelengths. Although they could not be jointly processed, more comprehensive pictures of ground deformation in both spatial and temporal domains can potentially be derived. Furthermore, with the free and open trend of spaceborne SAR data, automatic subsidence warning systems could be potentially developed to provide near real-time subsidence information and warnings.

Acknowledgments: This research is supported by Ministry of Science and Technology, Taiwan (grant numbers MOST-104-2116-M-008-022 and MOST-105-2922-I-008-028) and National Central University through the NCU International Student Scholarship. Optical imagery used are available in Google Earth and Bing Maps applications. TerraSAR-X imagery was provided by German Aerospace Center (DLR) through GEO3018 project. SRTM DEM was provided by the United States Geological Survey (USGS). We would like to thank three anonymous reviewers who had substantial contributions to improve the quality of the manuscript.

Author Contributions: The main idea of this research arose from the discussions between Tuan S. Le and Chung-Pai Chang. Tuan S. Le analyzed the data and wrote the manuscript. Figures were edited and annotated mainly based on Chung-Pai Chang's suggestions. Chung-Pai Chang made significant contributions to the Result and discussion section. Xuan T. Nguyen and Akano Yhokha contributed to the Study area and Conclusion sections. The manuscript was read and revised by all authors.

Conflicts of Interest: The authors declare no conflict of interest. 


\section{Appendix}

Table A1. Condition assessments of historical monuments and heritage assets in the Historical Centre of Hanoi.

\begin{tabular}{|c|c|c|c|c|c|c|}
\hline $\begin{array}{l}\text { Site } \\
\text { No. }\end{array}$ & Site Name & $\begin{array}{l}\text { No. of } \\
\text { SDFP }\end{array}$ & $\begin{array}{c}\text { Average } \\
\text { LoS Rate } \\
\text { (mm/year) }\end{array}$ & $\begin{array}{l}\text { Maximum } \\
\text { LoS Rate } \\
\text { (mm/year) }\end{array}$ & $\begin{array}{c}\text { Average } \\
\text { Vertical } \\
\text { Rate } \\
\text { (mm/year) }\end{array}$ & $\begin{array}{c}\text { Maximum } \\
\text { Vertical } \\
\text { Rate } \\
\text { (mm/year) }\end{array}$ \\
\hline $\mathrm{n} / \mathrm{a}$ & The Ceramic Mosaic Mural & 21,801 & -4.8 & -11.5 & -6 & -14.4 \\
\hline 1 & The Imperial Citadel of Thang Long & 21,976 & -1.0 & -3.7 & -1.2 & -4.7 \\
\hline 2 & Ba Dinh Square & 4066 & -0.9 & -2.3 & -1.1 & -2.9 \\
\hline 5 & Quan Thanh Temple & 68 & -1.0 & -2.0 & -1.3 & -2.5 \\
\hline 6 & $\begin{array}{c}\text { The Presidential Palace } \\
\text { (Indochina General Government) }\end{array}$ & 968 & -1.8 & -3.7 & -2.3 & -4.7 \\
\hline 7 & One Pillar Pagoda & 17 & -1.8 & -3.4 & -2.3 & -4.3 \\
\hline 8 & Hoe Nhai Pagoda & 41 & -4.1 & -6.0 & -4.8 & -7.5 \\
\hline 13 & St. Joseph's Cathedral & 851 & -3.4 & -7.9 & -4.3 & -9.9 \\
\hline 14 & Hanoi Roman Catholic Archdiocese & 273 & -8.0 & -12.3 & -10 & -15.5 \\
\hline 15 & Hoa Lo Heritage Prison & 90 & -1.3 & -2.7 & -1.6 & -3.4 \\
\hline 16 & Hanoi Opera House & 1793 & -3.0 & -4.5 & -3.8 & -5.7 \\
\hline 17 & Dong Da Mound & 4531 & -4.5 & -7.0 & -5.7 & -8.8 \\
\hline 18 & Hoang Cao Khai Imperial Tomb & 653 & -5.2 & -7.8 & -6.5 & -9.8 \\
\hline 19 & Kim Lien Temple & 77 & -2.0 & -3.7 & -2.5 & -4.7 \\
\hline 20 & Linh Son Pagoda & 129 & -11.5 & -14.7 & -14.5 & -18.5 \\
\hline
\end{tabular}

Table A2. The condition and interpreted causes of subsidence patterns observed in the Historical Centre of Hanoi.

\begin{tabular}{|c|c|c|c|c|c|c|}
\hline Label & $\begin{array}{c}\text { Subsidence } \\
\text { Location } \\
\text { (Represented } \\
\text { in Figure as } \\
\text { Listed) }\end{array}$ & $\begin{array}{c}\text { Average } \\
\text { LoS Rate } \\
\text { (mm/year) }\end{array}$ & $\begin{array}{c}\text { Average } \\
\text { Vertical } \\
\text { Rate } \\
\text { (mm/year) }\end{array}$ & $\begin{array}{l}\text { Distance to } \\
\text { Nearest } \\
\text { Construction } \\
\text { Site }(\mathrm{m}) \\
(2010-2013) \\
\end{array}$ & $\begin{array}{l}\text { Surface } \\
\text { Properties }\end{array}$ & $\begin{array}{l}\text { Interpreted Causes } \\
\text { of Subsidence }\end{array}$ \\
\hline S1 & $\begin{array}{l}\text { Hang Chao } \\
\text { (Figure 6a) }\end{array}$ & -10.1 & -12.7 & 95 & $\begin{array}{c}\text { Clay and } \\
\text { organic } \\
\text { matter }\end{array}$ & $\begin{array}{c}\text { Construction water } \\
\text { extraction }\end{array}$ \\
\hline S2 & $\begin{array}{l}\text { Thuy Khue } \\
\text { (Figure 6b) }\end{array}$ & -8.8 & -11 & 36 & Clay & $\begin{array}{c}\text { Construction water } \\
\text { extraction }\end{array}$ \\
\hline S3 & $\begin{array}{l}\text { Le Hong } \\
\text { Phong } \\
\text { (Figure 6c) }\end{array}$ & -11.4 & -14.3 & 104 & $\begin{array}{c}\text { Clay and } \\
\text { organic } \\
\text { matte }\end{array}$ & $\begin{array}{c}\text { Construction water } \\
\text { extraction }\end{array}$ \\
\hline S4 & $\begin{array}{l}\text { Phuc Tan } 1 \\
\text { (Figure 7a) }\end{array}$ & -8.3 & -10.4 & $\mathrm{n} / \mathrm{a}$ & Sand & Surface geology \\
\hline S5 & $\begin{array}{l}\text { Phuc Tan } 2 \\
\text { (Figure } 7 b \text { ) }\end{array}$ & -9.5 & -12 & $\mathrm{n} / \mathrm{a}$ & Sand & Surface geology \\
\hline S6 & $\begin{array}{l}\text { Hong Ha } \\
\text { (Figure 7c) }\end{array}$ & -10.9 & -13.7 & $\mathrm{n} / \mathrm{a}$ & Sand & Surface geology \\
\hline S7 & $\begin{array}{c}\text { Hang Trong } \\
\text { (Figure 8a) }\end{array}$ & -11.3 & -14.2 & 68 & Clay & $\begin{array}{c}\text { Construction water } \\
\text { extraction }\end{array}$ \\
\hline S8 & $\begin{array}{l}\text { Tho Xuong } \\
\text { (Figure } 8 \mathrm{~b} \text { ) }\end{array}$ & -9.8 & -12.3 & 65 & Clay & $\begin{array}{c}\text { Construction water } \\
\text { extraction }\end{array}$ \\
\hline
\end{tabular}


Table A2. Cont.

\begin{tabular}{|c|c|c|c|c|c|c|}
\hline Label & $\begin{array}{l}\text { Subsidence } \\
\text { Location } \\
\text { (Represented } \\
\text { in Figure as } \\
\text { Listed) }\end{array}$ & $\begin{array}{c}\text { Average } \\
\text { LoS Rate } \\
\text { (mm/year) }\end{array}$ & $\begin{array}{l}\text { Average } \\
\text { Vertical } \\
\text { Rate } \\
\text { (mm/year) }\end{array}$ & $\begin{array}{l}\text { Distance to } \\
\text { Nearest } \\
\text { Construction } \\
\text { Site }(\mathrm{m}) \\
(2010-2013)\end{array}$ & $\begin{array}{l}\text { Surface } \\
\text { Properties }\end{array}$ & $\begin{array}{l}\text { Interpreted Causes } \\
\text { of Subsidence }\end{array}$ \\
\hline S9 & Hang Gai & -8.9 & -11.2 & $\mathrm{n} / \mathrm{a}$ & Clay & $\mathrm{n} / \mathrm{a}$ \\
\hline S10 & $\begin{array}{l}\text { Lieu Giai } \\
\text { (Figure 9a) }\end{array}$ & -13.4 & -16.8 & 17 & $\begin{array}{l}\text { Clay and } \\
\text { organic } \\
\text { matter }\end{array}$ & $\begin{array}{c}\text { Construction } \\
\text { activities/Construction } \\
\text { water extraction }\end{array}$ \\
\hline S11 & $\begin{array}{l}\text { Dong Da } \\
\text { (Figure 9b) }\end{array}$ & -12.5 & -15.7 & 1 & $\begin{array}{c}\text { Clay and } \\
\text { organic } \\
\text { matter }\end{array}$ & $\begin{array}{l}\text { Construction } \\
\text { activities }\end{array}$ \\
\hline S12 & $\begin{array}{l}\text { Kim Hoa } \\
\text { (Figure 9c) }\end{array}$ & -14.4 & -18.1 & 123 & $\begin{array}{l}\text { Loamy } \\
\text { sand/clay }\end{array}$ & $\begin{array}{c}\text { Surface } \\
\text { geology/Domestic } \\
\text { water extraction }\end{array}$ \\
\hline S13 & $\begin{array}{l}\text { Thai Ha } \\
\text { (Figure 9d) }\end{array}$ & -6 & -7.5 & 21 & Loamy sand & $\begin{array}{c}\text { Surface } \\
\text { geology/Construction } \\
\text { water extraction }\end{array}$ \\
\hline S14 & $\begin{array}{c}\text { Nguyen } \\
\text { Luong Bang }\end{array}$ & -14.2 & -17.9 & 6 & Loamy sand & $\begin{array}{c}\text { Surface } \\
\text { geology/Construction } \\
\text { water extraction }\end{array}$ \\
\hline S15 & $\begin{array}{c}\text { Tran Khat } \\
\text { Chan } 1\end{array}$ & -14.1 & -17.7 & 96 & Clay & $\begin{array}{l}\text { Construction/Domestic } \\
\text { water extraction }\end{array}$ \\
\hline S16 & Bach Mai & -9.7 & -12.2 & $\mathrm{n} / \mathrm{a}$ & Clay & $\begin{array}{l}\text { Domestic water } \\
\text { extraction }\end{array}$ \\
\hline S17 & $\begin{array}{c}\text { Tran Khat } \\
\text { Chan } 2\end{array}$ & -11.8 & -14.8 & $\mathrm{n} / \mathrm{a}$ & Clay & $\begin{array}{c}\text { Domestic water } \\
\text { extraction }\end{array}$ \\
\hline S18 & Kim Nguu & -13.7 & -17.2 & $\mathrm{n} / \mathrm{a}$ & Clay & $\begin{array}{l}\text { Domestic water } \\
\text { extraction }\end{array}$ \\
\hline
\end{tabular}

\section{References}

1. Nguyen, Q.T.; Helm, D.C. Land subsidence due to ground water withdrawal in Hanoi, Vietnam. In Proceedings of the Fifth International Symposium on Land Subsidence, The Hague, The Netherlands, 16-20 October 1995.

2. Thu, T.M.; Fredlund, D.G. Modelling subsidence in the Hanoi city area, Vietnam. Can. Geotech. J. 2000, 37, 621-637.

3. Phi, T.H.; Strokova, L.A. Prediction maps of land subsidence caused by groundwater exploitation in Hanoi, Vietnam. Resour-Effict. Technol. 2015, 1, 80-89. [CrossRef]

4. Raucoules, D.; Carnec, C. DEM derivation and subsidence detection on Hanoi from ERS SAR Interferometry. In Proceedings of the FRINGE '99 Workshop: Advancing ERS SAR Interferometry from Applications towards Operations, Liège, Belgium, 10-12 November 1999; ESA SP-478. 2000.

5. Tran, V.A.; Masumoto, S.; Raghavan, V.; Shiono, K. Spatial distribution of subsidence in Hanoi detected by JERS-1 SAR interferometry. Geoinformatics 2007, 18, 3-13.

6. Dang, V.K.; Doubre, C.; Weber, C.; Gourmelen, N.; Masson, F. Recent land subsidence caused by the rapid urban development in the Hanoi region (Vietnam) using ALOS InSAR data. Nat. Hazards Earth Syst. Sci. 2014, 14, 657-674. [CrossRef]

7. Le, S.T.; Chang, C.P. Surface deformation assessments in Hanoi, Vietnam using ALOS PALSAR interferometry. In Proceedings of the 36th Asian Conference on Remote Sensing (ACRS 2015), Manila, Philippines, 19-23 October 2015.

8. Luo, Q.; Perissin, D.; Lin, H.; Zhang, Y.; Wang, W. Subsidence monitoring of Tianjin suburbs by TerraSAR-X Persistent Scatterers interferometry. IEEE J-STARS. 2014, 7, 1642-1650. [CrossRef] 
9. Report on Area, Population and Population Density in 2011 by Province. Available online: http:/ / www.gso.gov.vn/default.aspx?tabid=387\&idmid=3\&ItemID=12875 (accessed on 15 January 2016).

10. Mathers, S.; Zalasiewicz, J. Holocene sedimentary architecture of the Red River Delta, Vietnam. J. Coastal Res. 1999, 15, 314-325.

11. Nguyen, D.D. Geological map of Hanoi city; Northern Division of Planning and Investigation for Water Resources: Hanoi, Vietnam, 1996.

12. Prati, C.; Ferretti, A.; Perissin, D. Recent advances on surface ground deformation measurement by means of repeated space-borne SAR observations. J. Geodyn. 2010, 49, 161-170. [CrossRef]

13. Farr, T.G.; Rosen, P.A.; Caro, E.; Crippen, R.; Duren, R.; Hensley, S.; Kobrick, M.; Paller, M.; Rodriguez, E.; Roth, L.; et al. The Shuttle Radar Topography Mission. Rev. Geophys. 2007, 45. [CrossRef]

14. Reuter, H.I.; Nelson, A.; Jarvis, A. An evaluation of void-filling interpolation methods for SRTM data. Int. J. Geogr. Inf. Sci. 2007, 21, 983-1008. [CrossRef]

15. Lanari, R.; Lundgren, P.; Manzo, M.; Casu, F. Satellite radar interferometry time series analysis of surface deformation for Los Angeles, California. Geophys. Res. Lett. 2004, 31. [CrossRef]

16. Berardino, P.; Fornaro, G.; Lanari, R.; Sansosti, E. A new algorithm for surface deformation monitoring based on small baseline differential SAR interferograms. IEEE T. Geosci. Remote 2002, 40, 2375-2383. [CrossRef]

17. Hooper, A. A multi-temporal InSAR method incorporating both persistent scatterer and small baseline approaches. Geophys. Res. Lett. 2008, 35. [CrossRef]

18. Ketelaar, V.B.H. Satellite Radar Interferometry: Subsidence Monitoring Techniques; Springer: Berlin, Germany, 2009.

19. Sousa, J.J.; Hooper, A.J.; Hanssen, R.F.; Bastos, L.C.; Ruiz, A.M. Persistent Scatterer InSAR: A comparison of methodologies based on a model of temporal deformation vs. spatial correlation selection criteria. Remote Sens. Environ. 2011, 115, 2652-2663. [CrossRef]

20. Arıkan, M.; Hooper, A.; Hanssen, R. Radar time series analysis over West Anatolia. In Proceedings of the FRINGE 2009, Frascati, Italy, 30 November-4 December 2009; ESA SP-677. 2010. Available online: http://earth.eo.esa.int/workshops/fringe09/proceedings/papers/p1_25arik.pdf (accessed on 15 January 2016).

21. Hanssen, R.F. Radar Interferometry: Data Interpretation and Error Analysis; Kluwer Academic Publishers: Dordrecht, The Netherlands, 2001.

22. Hooper, A. Persistent Scatterer Radar Interferometry for Crustal Deformation Studies and Modeling of Volcanic Deformation. Ph.D. Thesis, Stanford University, Stanford, CA, USA, May 2006.

23. Chang, C.P.; Wang, C.T.; Chang, T.Y.; Chen, K.S.; Liang, L.S.; Pathier, E.; Angelier, J. Application of SAR interferometry to a large thrust deformation: the $1999 \mathrm{Mw}=7.6$ Chichi earthquake in central Taiwan. Geophys. J. Int. 2004, 159, 9-16. [CrossRef]

24. Massonnet, D.; Feigl, K.L. Radar interferometry and its application to changes in the Earth's surface. Rev. Geophys. 1998, 36, 441. [CrossRef]

25. Bürgmann, R.; Rosen, P.A.; Fielding, E.J. Synthetic Aperture Radar interferometry to measure Earth's surface topography and its deformation. Annu. Rev. Earth Pl. Sci. 2000, 28, 169-209. [CrossRef]

26. Goldstein, R.M.; Werner, C.L. Radar interferogram filtering for geophysical applications. Geophys. Res. Lett. 1998, 25, 4035-4038. [CrossRef]

27. Kampes, B.; Hanssen, R.F.; Perski, Z. Radar interferometry with public domain tools. In Proceedings of the FRINGE 2003 Workshop, Frascati, Italy, 1-5 December 2003; ESA SP-550. 2004. Available online: http:/ / doris.tudelft.nl/Literature/kampes03b.pdf (accessed on 15 January 2016).

28. Ferretti, A.; Prati, C.; Rocca, F. Permanent scatterers in SAR interferometry. IEEE Trans. Geosci. Remote 2001, 39, 8-20. [CrossRef]

29. Hooper, A.; Segall, P.; Zebker, H. Persistent scatterer interferometric synthetic aperture radar for crustal deformation analysis, with application to Volcán Alcedo, Galápagos. J. Geophys Res. 2007, 112. [CrossRef]

30. Hooper, A.; Zebker, H.; Segall, P.; Kampes, B. A new method for measuring deformation on volcanoes and other natural terrains using InSAR persistent scatterers. Geophys. Res. Lett. 2004, 31. [CrossRef]

31. Hooper, A.; Zebker, H.A. Phase unwrapping in three dimensions with application to InSAR time series. J. Opt. Soc. Am. A 2007, 24, 2737-2747. [CrossRef]

32. Peltzer, G.; Rosen, P.; Rogez, F.; Hudnut, K. Poroelastic rebound along the Landers 1992 earthquake surface rupture. J. Geophys Res. 1998, 103, 30131. [CrossRef] 
33. Sladen, J.A.; D`Hollander, R.D.; Krahn, J. The liquefaction of sands, a collapse surface approach. Can. Geotech. J. 1985, 22, 564-578. [CrossRef]

34. Jefferies, M.; Been, K. Soil liquefaction: A Critical State Approach, 2nd ed.; Crc Press: New York, NY, USA, 2015.

35. Martin, G.R.; Finn, W.D.L.; Seed, H.B. Fundamentals of Liquefaction Under Cyclic Loading; Department of Civil Engineering, University of British Columbia: Vancouver, BC, Canada, 1974.

36. Logan, W. Heritage planning in post-Doi Moi Hanoi: The national and international contributions. J. Am. Plann. Assoc. 1995, 61, 328-343. [CrossRef]

37. Cigna, F.; Lasaponara, R.; Masini, N.; Milillo, P.; Tapete, D. Persistent Scatterer Interferometry processing of COSMO-SkyMed StripMap HIMAGE time series to depict deformation of the Historic Centre of Rome, Italy. Remote Sens. 2014, 6, 12593-12618. [CrossRef]

(C) 2016 by the authors; licensee MDPI, Basel, Switzerland. This article is an open access article distributed under the terms and conditions of the Creative Commons Attribution (CC-BY) license (http://creativecommons.org/licenses/by/4.0/). 